\title{
NBS
}

JBLICATIONS

\section{NBSIR 82-2561}

\section{NBS Portable Ambient Particulate Sampler}

U.S. DEPARTMENT OF COMMERCE National Bureau of Standards Center for Analytical Chemistry Washington, DC 20234

\section{November 1982}

Final Report

Issued January 1983

\section{Prepared for:}

nvironmental Monitoring Systems Laboratory nvironmental Protection Agency esearch Triangle Park, NC 27711 

NBSIR 82-2561

NBS PORTABLE AMBIENT PARTICULATE SAMPLER

Robert A. Fletcher and David S. Bright

U.S. DEPARTMENT OF COMMERCE

National Bureau of Standards

Center for Analytical Chemistry

Washington, DC 20234

November 1982

Final Report

Issued January 1983

Prepared for:

Environmental Monitoring Systems Laboratory

Environmental Protection Agency

Research Triangle Park, NC 27711

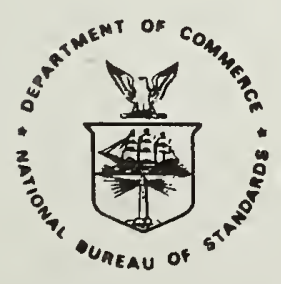

U.S. DEPARTMENT OF COMMERCE, Malcolm Baldrige, Secretary NATIONAL BUREAU OF STANDARDS. Ernest Ambler, Director 

The NBS portable ambient particulate sampler is designed to collect the respirable and inhalable particle size fractions at a sampling rate of $6 \mathrm{~L} / \mathrm{min}$ for 24 hour sampling periods. Particulates are fractionated and collected by series filtration. The collection efficiency of the inlet is measured by comparison with isokinetic probes in the wind tunnel. The collection efficiency and sampling size characteristics of two small personal cyclone samplers are also reported.

This work was sponsored by the Environmental Protection Agency under interagency agreement no. $\mathrm{AD}-13-\mathrm{F}-1-535-0$. 
CONTENTS

Abstract . . . . . . . . . . . . . . . . . . . . iii

Figures. . . . . . . . . . . . . . . . . . . . . . v v

Acknowledgements . . . . . . . . . . . . . . . . . vi

1. Introduction ....................... 1

2. Conclusions. . . . . . . . . . . . . . . . 3

3. Recommendations for Future Work. . . . . . . . . . . . 4

4. Designing the NBS Sampler . . . . . . . . . . . 5

5. Testing of Sampler Components . . . . . . . . . . . 10

6. Sampler Noise Measurements . . . . . . . . . . . 16

7. Wind Tunnel Test of Inlet. . . . . . . . . . . . . 18

8. Cut Test of Cyclones . . . . . . . . . . . . . 23

9. Atomizer Size Calibration. . . . . . . . . . . . . 27

References . . . . . . . . . . . . . . . . . 29 Appendices

A. Parts List . . . . . . . . . . . . . . 31

B. User Instructions . . . . . . . . . . . . . 35 


\section{FIGURES}

Number

Page

1 Schematic of sampler . . . . . . . . . . . . . . 2

2 Schematic of inlet . . . . . . . . . . . . . 7

3 Pump efficiency test . . . . . . . . . . . . . . 9

4 Battery life time test . . . . . . . . . . . . . . 11

5 Pulsation dampening test . . . . . . . . . . . . . 12

6 Coarse filter particle size cut test and effects of filter

loading . . . . . . . . . . . . . . . 14

7 Sampler inlet cut test . . . . . . . . . . . . . 15

8 Sampler noise measurements . . . . . . . . . . . . 17

9 Wind tunnel. . . . . . . . . . . . . . . . 19

10 Effect of wind speed on inlet sampling efficiency. . . . . . . . 20

11 Horizontal particle concentration profile . . . . . . . . . 22

11 Effect of wind speed on inlet collection efficiency . . . . . . . 22

12 Cyclone cut test . . . . . . . . . . . . . . . . 25

13 Effect of wind speed on cyclone collection efficiency . . . . . 26

14 Atomizer size distribution . . . . . . . . . . . . . 28 


\section{ACKNOWLEDGEMENTS}

The authors wish to thank Dr. John D. Spengler and co-workers (Harvard School of Public Health) for helpful discussions and the loan of a sampler. The authors would also like to thank Drs. Larry Doemeny and Paul Baron of NIOSH and T. Dzubay and R. K. Stevens of EPA for advice during the early stages of the project. We would like to thank Dr. Ben Liu for his advice with respect to wind tunnel sampler testing and Dr. Walter Johr and Steve Wall for use of their inlet design. 


\section{SECTION 1}

\section{INTRODUCTION}

We have developed a portable ambient particulate sampler that collects both inhalable $(\leq 15 \mu \mathrm{m})$ (1) and respirable (up to $3 \mu \mathrm{m}$ ) particulates for use in personal exposure monitoring applications. The NBS sampler is designed to complement and supplement exposure monitoring data obtained by existing area sampling programs. This has become an important issue based on evidence that personal exposure is often not accurately reflected by area sampling (2). Also, exposures can be appreciable in confined areas ( 3 ) where area samplers are rarely placed. Although existing personal samplers might perhaps be modified to collect the inhalable fraction as well as the respirable fraction, there are other reasons for developing another sampler. First, to fit easily into the present sampling program, the sampler has to run for 8 to 24 hours per battery charging. Also, ambient atmospheric particle mass concentration levels are 10 to 100 micrograms per cubic meter. Obtaining sufficient sample for gravimetric analysis at such concentrations requires a flow rate that is greater than that available with any current personal sampler or pump.

This paper describes the design of the NBS sampler shown in Figure 1 and reports the results of tests performed on prototypes. The particle collection efficiency of the sampler inlet has been characterized for wind conditions representative of indoor and calm outdoor air. We describe results indicating that for particles larger than 5-7 micrometer diameter the sampler may either over sample or under sample, depending on wind velocity and direction.

Two small cyclone samplers, the $10 \mathrm{~mm}$ Nylon and the H\&H cyclone sampler*, have received wide use in industrial and mining environments. This report also discusses our test results for these samplers.

\footnotetext{
* In order to adequately describe materials and experimental procedures, it was occasionally necessary to identify commercial products by manufacturer's name or label. In no instance does such identification imply endorsement by the National Bureau of Standards nor does it imply that the particular products or equipment is necessarily the best available for that purpose.
} 


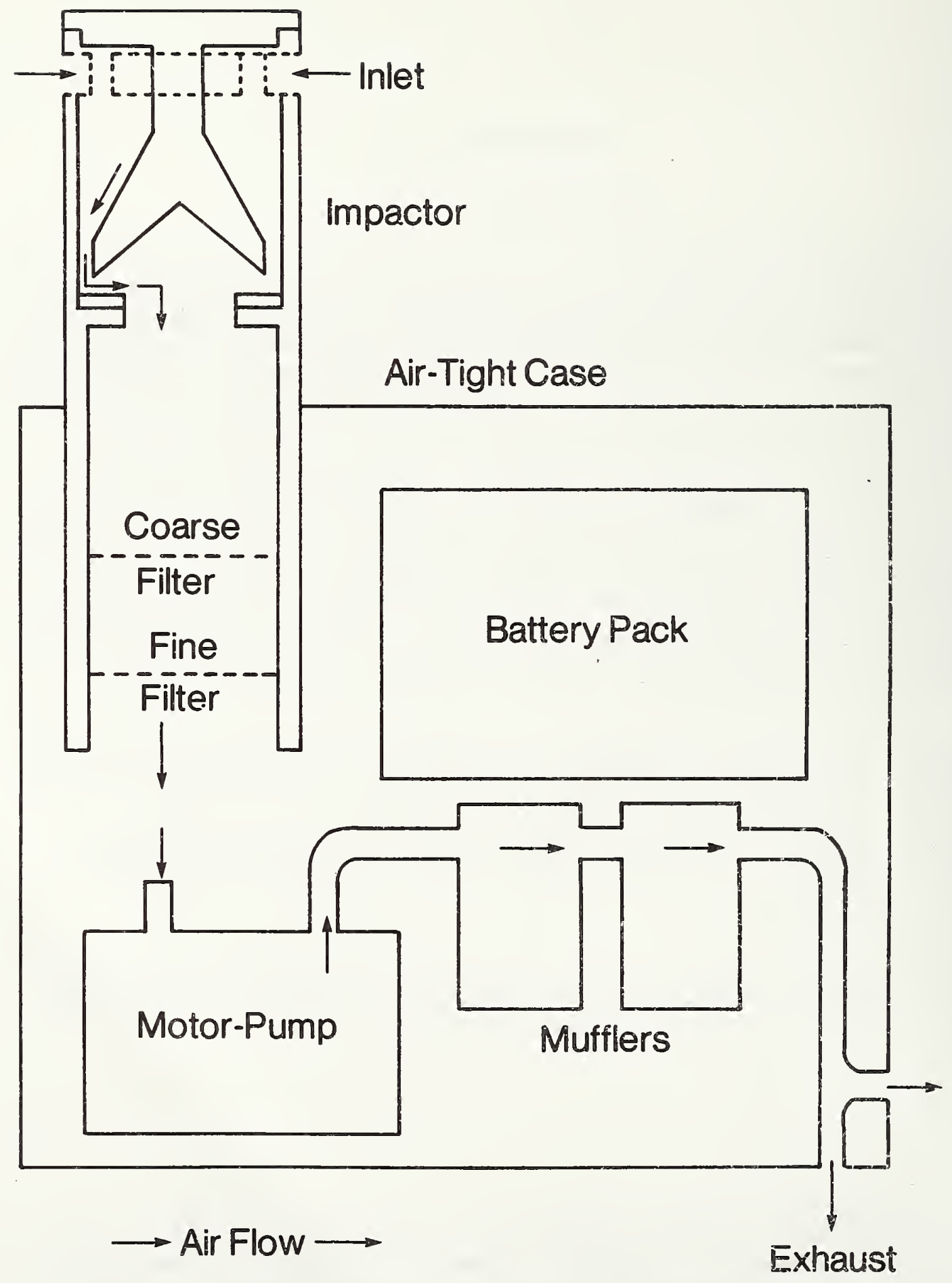

Figure 1. Schematic diagram of the sampler. 


\section{SECTION 2}

\section{CONCLUSIONS}

The NBS portable particulate sampler collects the respirable and inhalable size fractions of airborne particles. The collection efficiency has been characterized for wind speeds ranging from indoor $(0.15-0.5 \mathrm{~m} / \mathrm{s})$ to moderate outdoor $(2.4 \mathrm{~m} / \mathrm{s})$ conditions. Flow rates of 5.5 to $6.5 \mathrm{~L} / \mathrm{min}$ can be sustained from 20 to 60 hours by the $1.6 \mathrm{~kg}$ ( 4 pound) sampler.

The sampling efficiency of the two cyclone samplers tested were found to be slightly wind directional and orientation independent for $1 \mu \mathrm{m}$ mass mean diameter particles in the wind tunnel. The cut-points (diameter of particle having $50 \%$ penetration through the cyclone sampler) were found to be the expected values. 


\section{SECTION 3}

RECOMMENDATIONS FOR FUTURE WORK

Our recommendations for future research on the NBS sampler are:

1. To continue modification and testing of the inlet to reduce the effects of wind speed and direction.

2. To adapt gas monitors for inclusion into the portable particle sampler.

3. To field test and further refine the sampler to make it more rugged and dependable. 


\section{SECTION 4}

\section{DESIGNING THE NBS SAMPLER}

The NBS sampler was designed to be as small and portable as possible and yet comply with the following design constraints:

- The sampler should have well defined, stable cut points with respect to particle size.

- The samples (as with the standard EPA area samplers) should be collected on filters for subsequent weighing and chemical analysis.

- The sampler should have as high a sampling flow rate as possible since ambient particle concentrations are typically low and a $>100 \mu \mathrm{g}$ particle sample per filter is necessary for a gravimetric measurement uncertainty of $\leq 10 \%$.

- X-ray fluorescence, a widely used method for elemental analysis of filter samples, requires the sample be in an even, homogeneous layer on the filter (4).

- To be acceptable to volunteers participating in exposure studies, the sampler must be light, quiet and inconspicuous.

- To be able to sample at high flow rates for long time periods and still be small and light weight, the sampler must have energy efficient components. This means that the sampler air path must have a low pressure drop and that the motor-pump unit have low internal losses.

\section{DEVICE FOR THE $3 \mu \mathrm{m}$ RESPIRABLE CUT}

The NBS sampler (figure 1) uses a $6.8 \mu \mathrm{m}$ pore size, Apiezon L coated Nuclepore filter to achieve the separation $(5,6)$ of the inhalable and respirable fractions. In addition to serving as the collection substrate for the coarse or inhalable particle fraction, it has the advantages of being inexpensive, light weight, and having only $2.5 \mathrm{~cm}$ (one inch) of water pressure drop. The size cut characteristics are adequate despite the inherent problems of loading and bounce $(7,8)$ associated with membrane filters. 
The following samplers were also considered for separating the respirable and inhalable particle size fractions, but were not chosen for the reasons indicated:

a. Cyclone: A $10 \mathrm{~mm}$ nylon cyclone is commonly used for industrial (9) and ambient (10) samplers that collect only the respirable fraction. If it were used for the NBS sampler to collect the inhalable fraction it would be necessary to wash the cyclone to retrieve the inhalable fraction, and subsequent handling and preparation would be required for analysis.

b. Impactor: Single orifice impactors have been used for personal samplers (11), however, a heavy grease coating is needed to minimize bounce, and the sample is deposited in a spot rather than evenly over the filter. Both of these sampling effects complicate subsequent analysis.

c. Micro-orifice impactor: This device (12) may be used without a greased surface, and will deposit the sample in a sufficiently even layer for $x$-ray fluorescence analysis. It is a future possibility for the NBS sampler, but it is still in the developmental stage and would be very expensive.

d. Virtual impactor: This device is used in the dichotomous sampler, but is not used for the NBS sampler because it is heavy and complicated. Also, unless cascade impactors are used, some of the fine fraction would always contaminate the coarse fraction.

e. Electrical Mobility Analyzer: This device has a very low pressure drop and works well for particles smaller than 1 micrometer, but not well for larger particles. It is large and thus would not be practical as a portable/ personal sampler. Also, the high voltages required by the instrument are a potential personal hazard.

DEVICE FOR INHALABLE CUT AND INLET

All particles greater than the upper size limit of the inhalable fraction (10 or $15 \mu \mathrm{m}$ (13-17) must be eliminated by the inlet. Also, the sampling efficiency of the inlet should be minimally affected by wind speed and direction (18-20). Several inlets were designed and tested for the dichotomous sampler $(21,22)$, but most of these inlets, even when scaled down to operate at $6 \mathrm{~L} / \mathrm{min}$ were larger than our entire sampler. Therefore, we used part of an inlet (Figure 2) designed by Walter John (22.). When scaled for $6 \mathrm{~L} / \mathrm{min}$, this inlet is small and includes an impactor which can be designed to cut at 7,10 , or $15 \mu \mathrm{m}$ and to minimize bounce even when heavily loaded. 


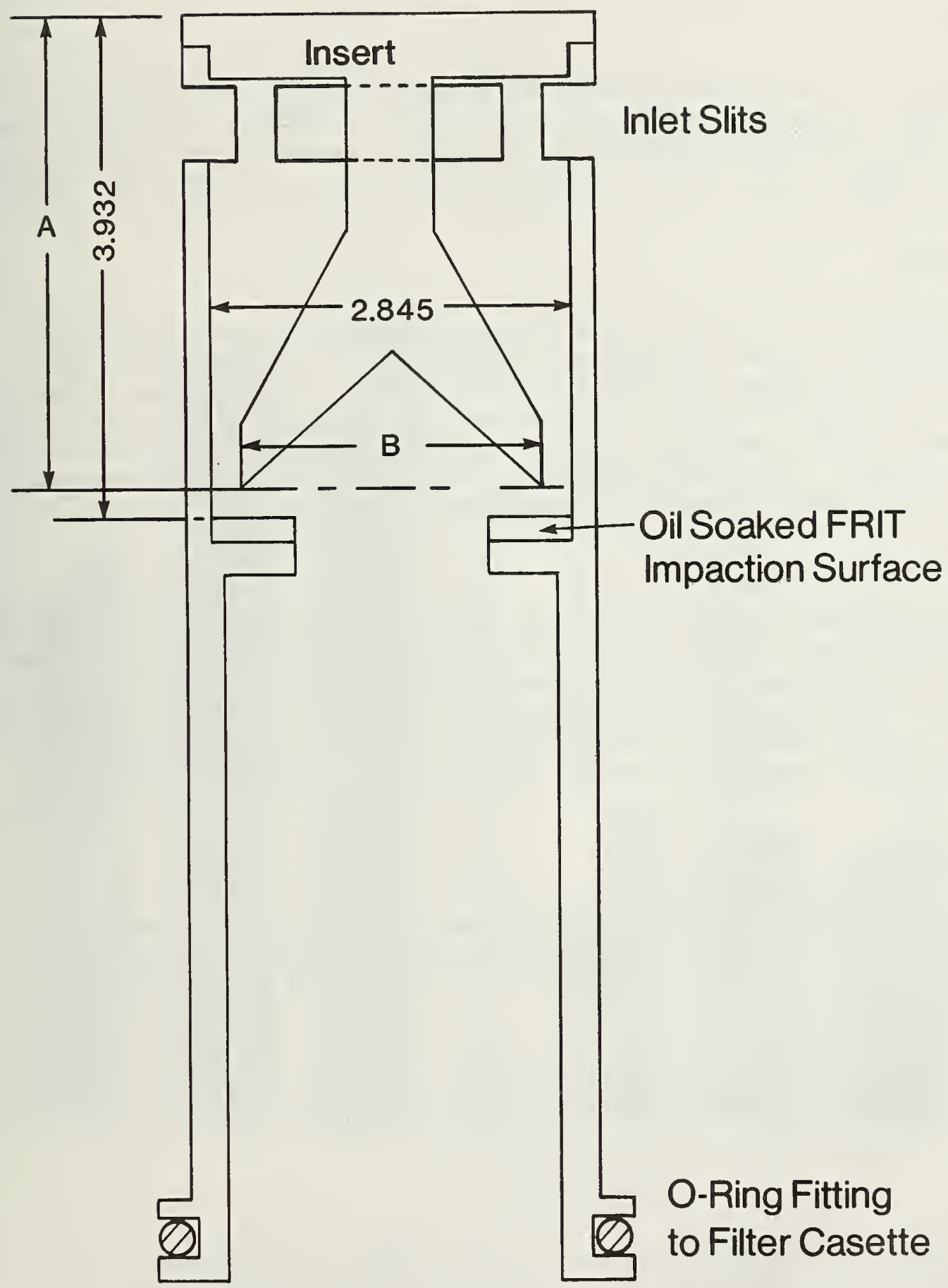

- Figure 2. Cross section of the inlet, to scale. Full length $=9.5 \mathrm{~cm}, 15 \mu \mathrm{m}$ insert shown, (critical dimensions in $\mathrm{cm}$ ).

Critical Dimensions for Funnel Inserts

\begin{tabular}{|c|c|c|}
\hline $\begin{array}{l}\text { Cut Point } \\
\quad(\mu \mathrm{m}) \\
\end{array}$ & $\begin{array}{c}\mathrm{A} \\
(\mathrm{cm}) \\
\end{array}$ & $\begin{array}{l}\mathrm{B} \\
(\mathrm{cm}) \\
\end{array}$ \\
\hline 15 & 3.696 & 2.372 \\
\hline 10 & 3.863 & 2.568 \\
\hline 7 & 3.871 & 2.675 \\
\hline
\end{tabular}




\section{FINE FILTER}

Ideally, the fine filter should be an absolute filter and have a low pressure drop. Glass fiber filters that have these characteristics are too flimsy, massive, and/or hydrophilic. We chose a porous polytetraflioroethylene (PTFE) fiber filter (23) as the fine filter for collecting the respirable $(\leq 3 \mu \mathrm{m})$ fraction.

\section{FILTER PACKAGE}

The coarse and fine filters are strong enough to be mounted without support pads between the $37 \mathrm{~mm}$ plastic rings of a filter cassette. This filter cassette provides a disposable container for collection and storage, it minimizes filter contamination, promotes smooth sample deposition, and has a low pressure drop. The total sampler pressure drop at $6 \mathrm{~L} / \mathrm{min}$ is only 13 to $15 \mathrm{~cm}$ of water. The inlet, impactor, and tubing add oniy a few mm water pressure drop to that of the filter cassette.

MOTOR-PUMP UNIT

Batteries make up over half of the total weight of the sampler. Battery weight, within a given battery type, is roughly proportional to the stored energy. Therefore, we chose the commercial pump-motor unit that was most efficient at $6 \mathrm{~L} / \mathrm{min}$ and $15 \mathrm{~cm}$ ( 6 inches) of water pressure drop (Figure 3). Fortunately, the Bendix unit, besides being the most energy efficient for these operational conditions, was also the quietest unit when inside the sampler case.

\section{AUXILLIARY PARTS}

To keep the sampler weight at a minimum, a battery charger was not incorporated in the sampler. The batteries may be charged externally and changed when the filter pack is changed. There is easy access to boch the battery and filter packs. 


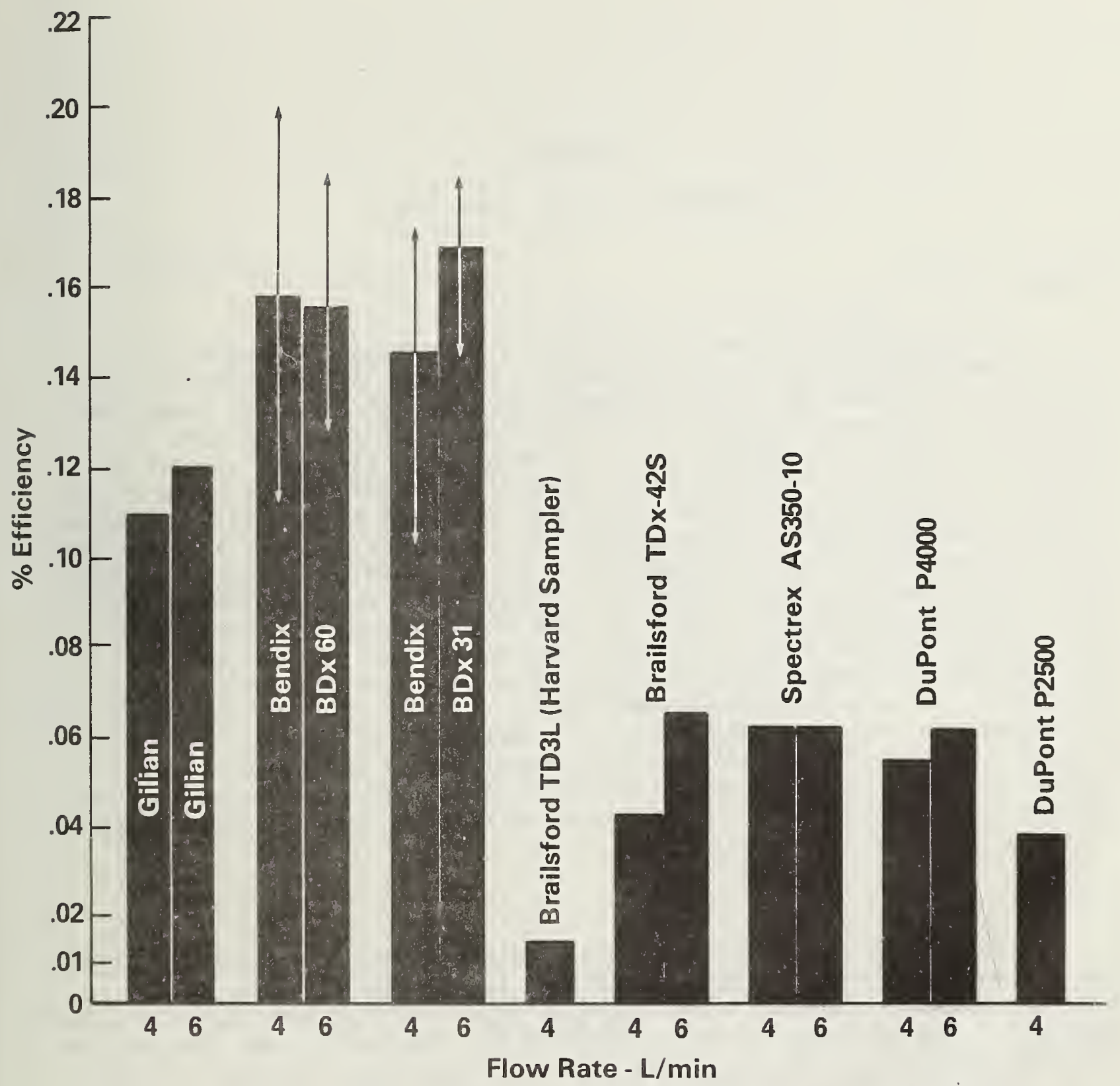

Figure 3. Pump efficiency. Efficiencies of various commercial motor-pump units for a pressure drop (load on pump) of $15 \mathrm{~cm}$ ( 6 inches) of water. Efficiency is calculated by dividing the work done per unit time in drawing air through a restriction, by the electrical power consumed by the motor. Comparative efficiencies may be very different at other pressure drops. 


\section{SECTION 5}

\section{TESTING OF SAMPLER COMPONENTS}

\section{BATTERY - PUMP}

Because particle concentration values are dependent on sampler flow rate, a uniform, stable flow is desirable. The best flow rate control over long periods of time was obtained using nickel-cadmium batteries connected directly to the motor (see page 34 ). This combination held the flow rate constant to within $10 \%$ (Figure 4 ). To determine the effect of changes in flow rate on sampler performance, we compared measurements at $6 \mathrm{~L} / \mathrm{min}$ and $4 \mathrm{~L} / \mathrm{min}$. This reduction in flow rate (33\%) increases by only $7 \%$ the diameter of particles collected at $50 \%$ efficiency on the coarse filter. Assuming that the inlet impactor behaves similarly to a single round jet impactor, a reduction of the flow rate from $6 \mathrm{~L} / \mathrm{min}$ to $4 \mathrm{~L} / \mathrm{min}$ would raise the diameter for $50 \%$ collection efficiency by on 1 y $7 \%$. For normal atmospheric conditions, i.e., $20-50 \mu \mathrm{g} / \mathrm{m}^{3}$ particles of $<3 \mu \mathrm{m}$ diameter, the flow restriction due to the fine filter clogging will reduce the flow rate less than $10 \%$. The uncertainty in air volume measurement is not critical since at these particle concentrations, particle mass can only be determined to $10 \%$. We therefore judged additional flow control for the sampler not to be necessary. In a 8 or $24 \mathrm{~h}$ integral sampling period, filter clogging may become a problem when ambient particle concentration levels are exceedingly high. A short sampling interval solves this problem.

CASE

We selected a strong, aluminum case, $10 \times 10 \times 18 \mathrm{~cm}$, which has a handle and hinged, gasketed 1id. Because the case can be made airtight, the internal volume serves as a pulse dampener which compares favorably with other methods of pump pulsation dampening (Figure 5). The sealed case also muffles the pump noise.

\section{FINE FILTER}

Both the fine and coarse filters are sturdy and are weight-stable to a few micrograms. To obtain filter weights to this precision, however, it is necessary to equilibrate the filters in the weighing room and neutralize surface electrical charge on the filters and balance compartment with 500 microcurie Polonium ionizing units.

The fine filter causes most of the pressure drop in the sampler. To minimize the power requirements (pump capacity) of the sampler, we therefore 


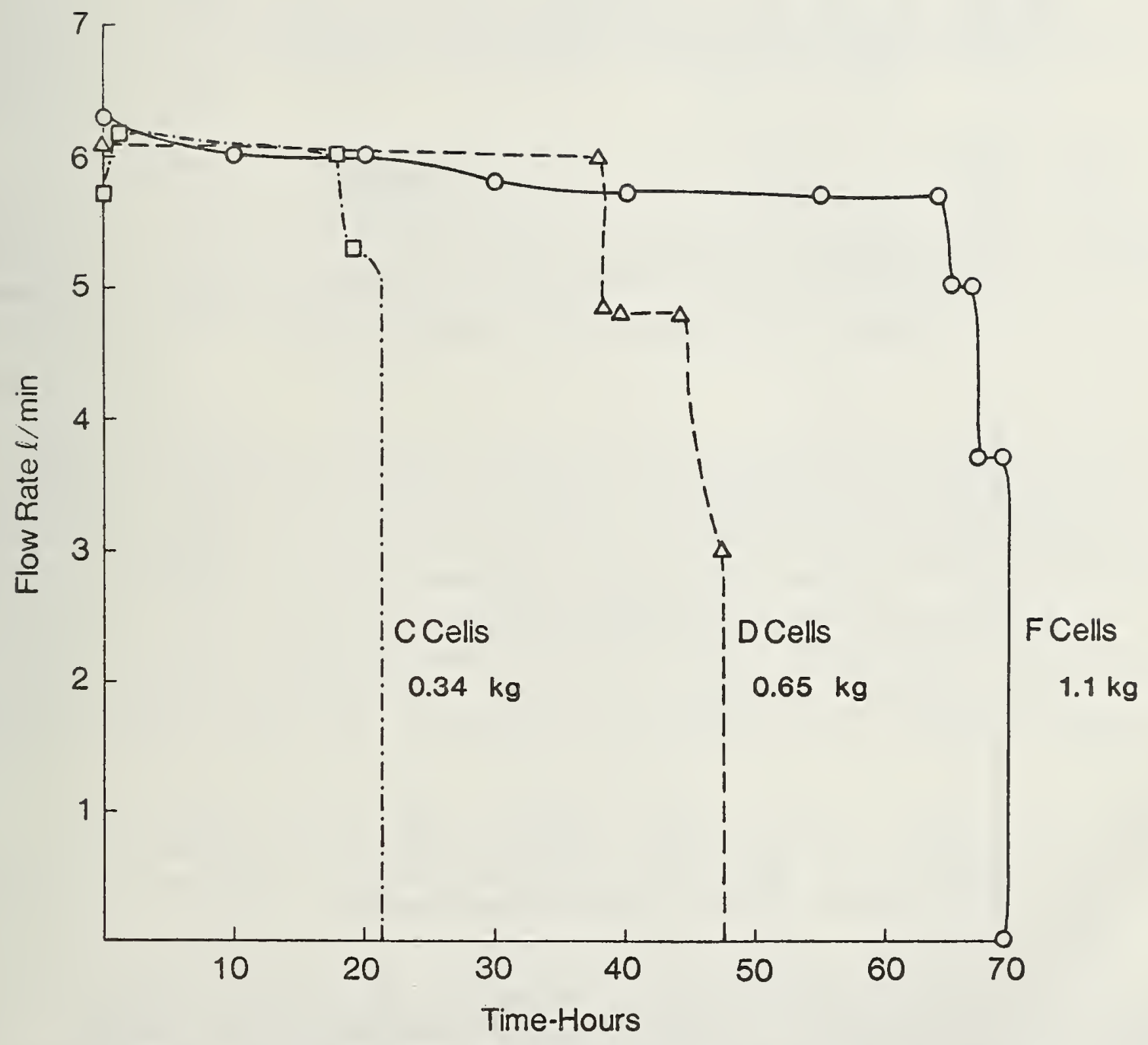

Figure 4. Battery pack lifetime. A freshly charged battery pack was inserted into the sampler and the flow rate monitored with a strip chart recorder. Note the maintenance of a fairly constant flow rate for most of the life of the battery pack. 


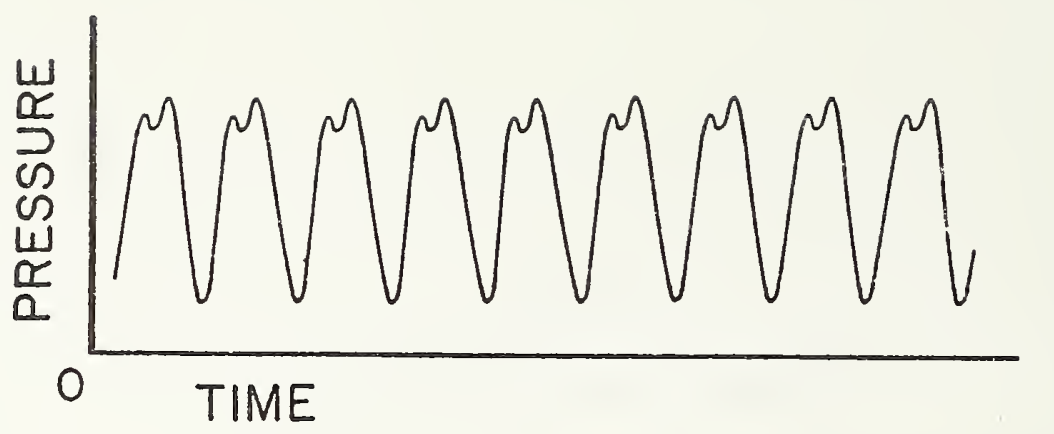

A
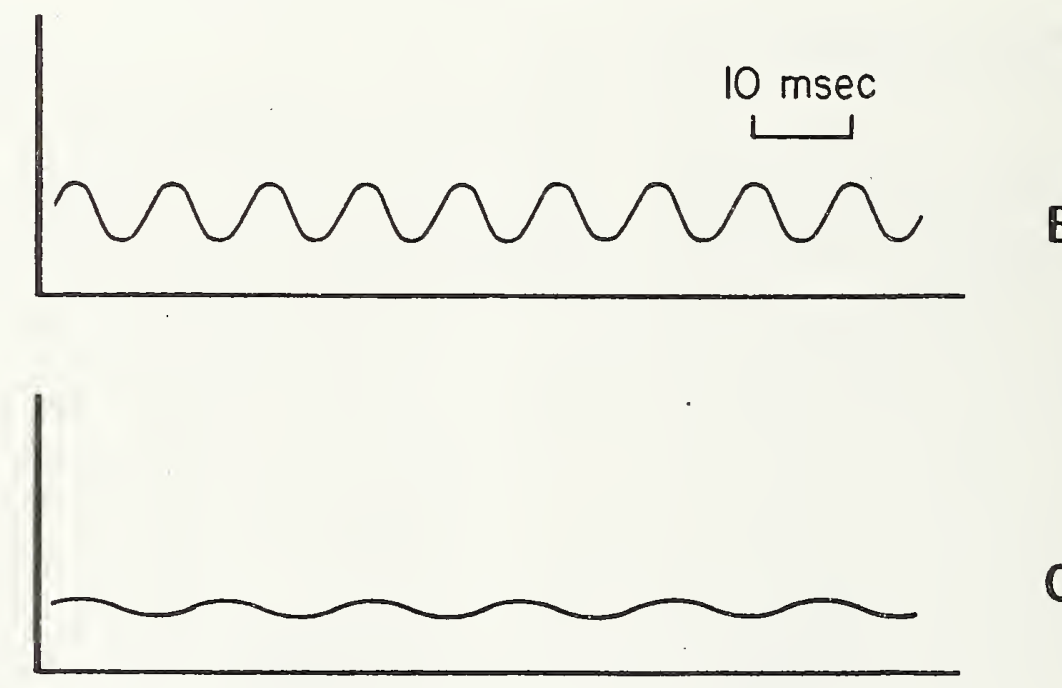

C

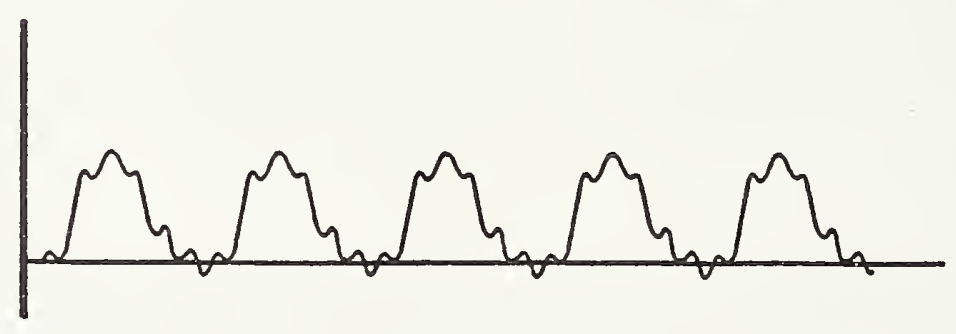

B

D

Figure 5. Pulsation dampening tests. Because the suction from diaphragm pumps is highly pulsatile, a dampener is needed between the pump and the particle collection elements. The oscilloscope tracings here compare the air flow through the inlet and coarse filter with various dampeners by showing the time variation of the pressure differential with respect to ambient pressure, measured just behind the coarse filter. In $A$, with no dampener present, the pulses are $50 \%$ excursions from the steady flow rate. This is improved in $B$, with a flexible rubber thimble dampener (used in the Bendix Super Samplers). The NBS sampler, C, gives virtually steady flow. D shows the corresponding measurement for the Harvard sampler (see acknowledgement) with different components: single piston Brailsford pump $(1.71 / \mathrm{min}), 3 \mathrm{~cm}$ bladder dampener, low porosity PTFE membrane filter, $2 \mathrm{~cm}$ "tee" connection (pressure measured here), and a $10 \mathrm{~mm}$ cyclone. The small excursions below the baseline show that the pulses are large enough to momentarily reverse the direction of flow. 
selected the most porous filter available that still collects most of the fine (respirable) particles. The filter selected is a $3 \mu \mathrm{m}$ pore PTFE fiber filter. This filter causes only 8 to $10 \mathrm{~cm}$ of water pressure drop at $6 \mathrm{~L} / \mathrm{min}$, yet it collects over $98 \%$ of all the fine particles. The worst loss (2\%) occurs for monodisperse $0.1 \mu \mathrm{m} \mathrm{NaCl}$ particles. These particles were generated with an atomizer, dried, and the monodisperse $0.1 \mu \mathrm{m}$ diameter fraction selected by an aerosol mobility classifier. The aerosol was detected with a condensation nuclei counter. These tests gave results similar to those of Liu et al., (23).

To determine the filter loadings that can be achieved before clogging occurs, the filter was loaded by sampling in a cigarette smoke-laden room until a reduction in the flow rate was observed. This took several days of sampling. No reduction in the flow rate for filter loadings up to 100 micrograms was observed; and flow rate charges of on $1 y-7 \%$ and $-12 \%$ for filter loadings of 220 and 400 micrograms, respectively, were noted.

\section{COARSE FILTER}

The particle size cut point of the coarse filter was determined for clean and ambient dust loaded filters. The filter penetration characteristics of monodisperse aerosol (produced by a vibrating orifice monodispers generator (24)) were measured with a Climet optical particle counter. If $C=$ number of particles without the filter and $\mathrm{C}_{\mathrm{f}}=$ number of particles with the filter in

the particle counter inlet, then the collection efficiency is defined as $\left(\mathrm{C}-\mathrm{C}_{\mathrm{f}}\right) / \mathrm{C}$. The aerodynamic diameters of the aerosol particles were determined by measuring their sedimentation velocity in air and calculating their diameter using Stokes law. Diameters smaller than 3 or $4 \mu \mathrm{m}$ were obtained by dilution of the solution used to generate larger particles of known diameter.

Liquid test particles were generated using DOP and solid particles using solution of ammonium fluoroscein or ammonium sulfate. No difference was noted between the two types of solid particles in these tests. Results of the tests are shown in Figure 6. The cut curves are broad, but the curves for solid particles closely match the AEC definition (9) for the respirable size distribution. The filter collects the liquid particles more efficiently. This indicates that the solid particles still experience some particle bounce despite the grease coating on the filter. The filter becomes more efficient as the loading increases for both liquid and solid particles because the effective pore size becomes smaller. The change with loading is less for solid particles. John et al., (8) attribute this to the fact that grease coating on the periphery of the pore is partly covered with dust, resulting in more bounce of the solid particles which counteracts the effect of decreasing pore size. The cut point for liquid particles is $2.3 \mu \mathrm{m}$ and for solid particles is $3.5 \mu \mathrm{m}$. The cut data (figure 6 ) indicates there is considerable variability in the cut point depending upon the sticking properties of the particles passing through the Nuclepore filter. However, the range of variability $(2.3-3.5 \mu \mathrm{m})$ fortuitously coincides with the broad minimum in the natural ambient particle mass distribution (25). Thus the coarse and fine particle fractions collected by the NBS sampler should correlate well with analogous fractions taken by accepted sampling devices such as the dichotomous sampler. 


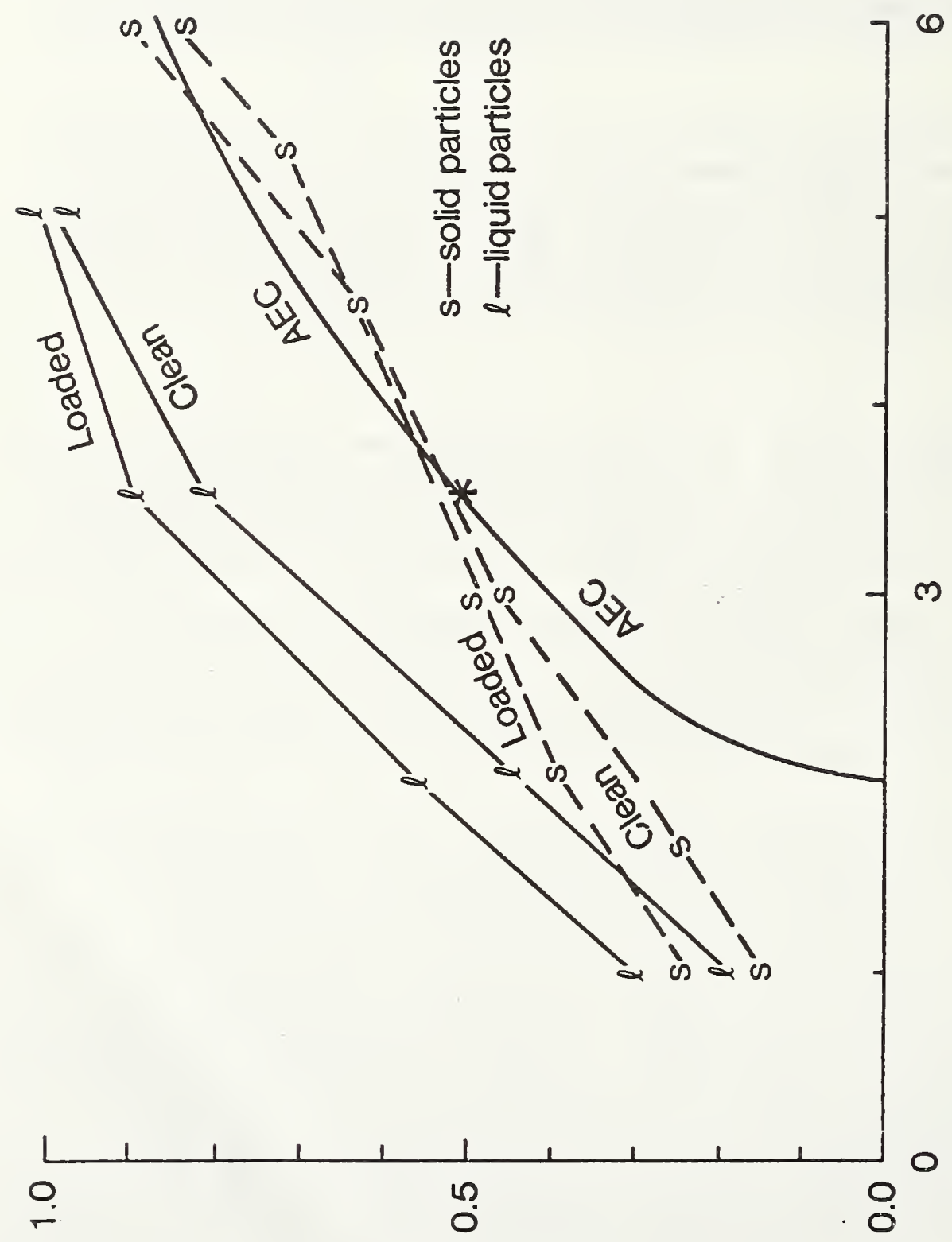

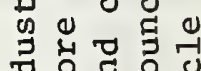

न

Ty 00 品

320

전유 웅

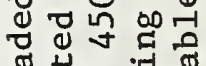

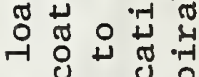

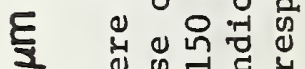

文

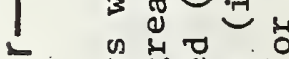

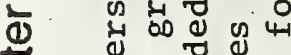

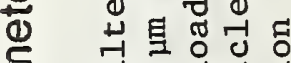

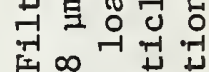
- मा क्ष 00 元 i $0^{4-1} 0$ 岸呵

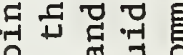
出 क 可 导

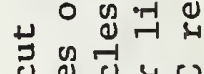
거에워 पु

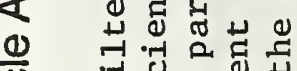

은 $\quad \begin{array}{r}-1 \\ -\pi\end{array}$

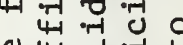

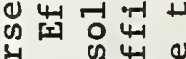

क्ष क्यू कू

मृ प्र

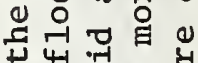
可 5 कo द्रे की 变频 出

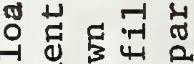
岁导志氜 मा पै 过

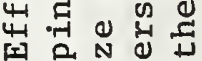
되 용

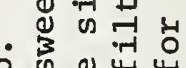

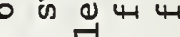

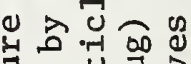

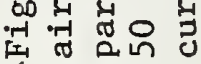




\section{INLET IMPACTOR}

The cut characteristics of the inlet (Figure 7) were determined with the same test apparatus as above except that oleic acid particulate was used. Results are also shown in Figure 7 for other inserts which were designed to cut at 10 and $7 \mu \mathrm{m}$ in addition to the $15 \mu \mathrm{m}$ cut.

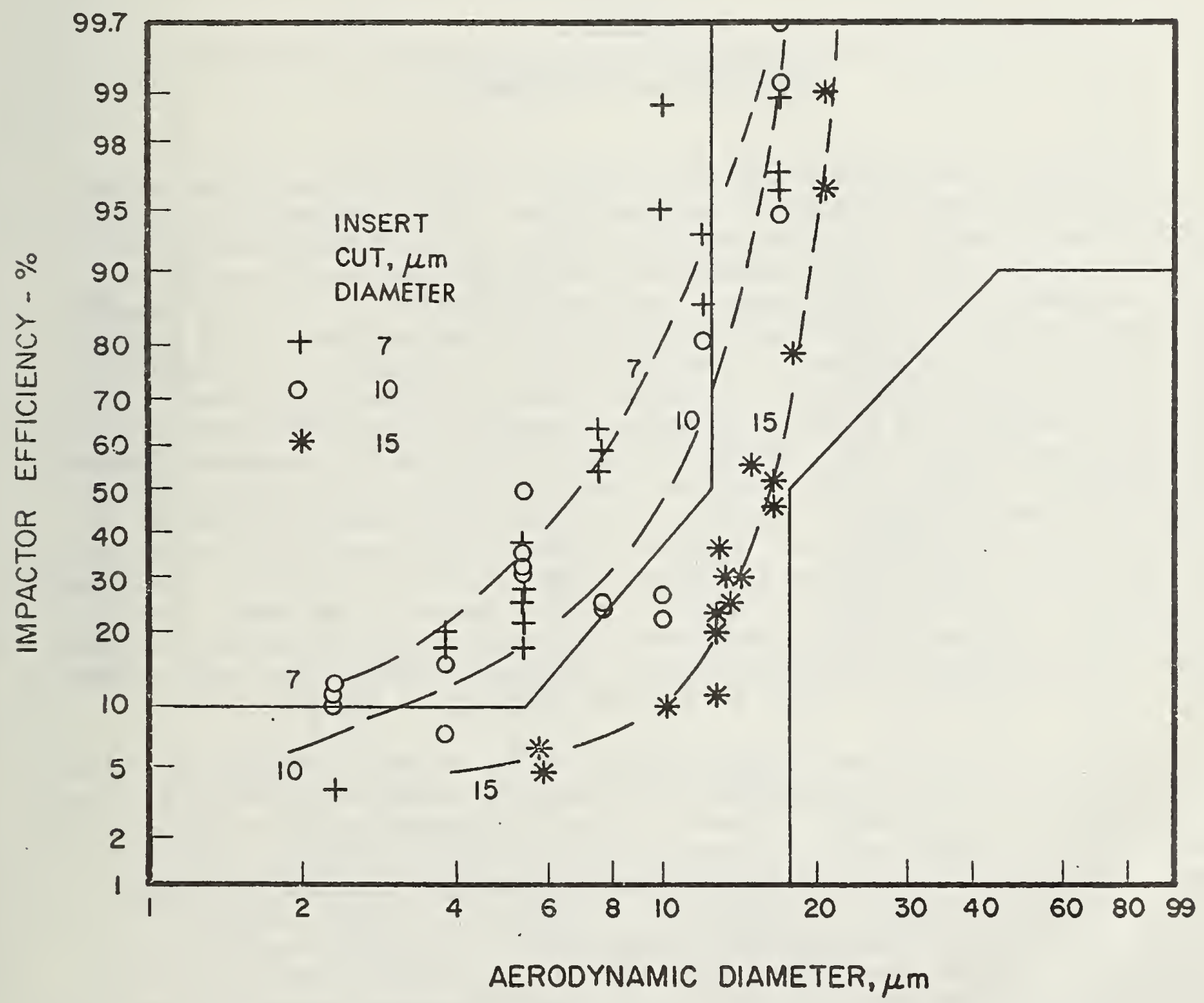

Figure 7. Sampler inlet cut test. The results of a pseudostatic test on the inlet impactor show the inlet impaction or removal efficiency for large particles. The data points for the $15 \mu \mathrm{m}$ insert fall within the recommended region for inhalable particles as of 1980 (26). The boxed in region in the upper left and lower right are forbidden regions. If $\mathrm{C}$ is the particle count with the funnel insert removed, and $C_{f}$ is the particle count with the funnel in place, then impaction efficiency $=\left(\mathrm{C}-\mathrm{C}_{\mathrm{f}}\right) / \mathrm{C}$. The 7 and $10 \mathrm{\mu m}$ inserts were designed and tested to meet possible revised definitions of inhalable particles. 


\section{SECTION 6}

\section{SAMPLER NOISE MEASUREMENTS}

To obtain the quietest sampler possible we made noise measurements of various motor-pumps and sampler configurations. The measurements consisted of frequency spectra and total RMS noise measurements. Measurements were made in a $55 \times 55 \times 75 \mathrm{~cm}$ cardboard box completely lined with 5 to $10 \mathrm{~cm}$ of foam rubber with a high quality microphone placed $60 \mathrm{~cm}$ from the sampler. Signals from the microphone were amplified and then analyzed with a Nicolet $440 \mathrm{~A}$ audio spectrum analyzer. Each spectrum is a summation of 32 single spectra minus 32 background noise spectra taken with the pump turned off. With the sampler case closed, differences between various pumps were hard to detect above $500 \mathrm{~Hz}$. This is because the case muffles high frequency sounds. Representative $500 \mathrm{~Hz}$ spectra for two pumps and for the case being open or shut are shown in Figure 8. Curves 1 and 2 show the reduction in noise attained by closing the case. The most notable difference is the elimination of the peak at $350 \mathrm{~Hz}$ (curve 3) when the case is closed (curve 2). This peak corresponded to an annoying pulsing or rattling sound of the pump. The differences between curves 2 and 3 and the corresponding RMS noise differences (see caption of Figure 8) do not seem to adequately reflect the large difference in "annoyance level" that occurs when the sampler case is closed.

Curves 1 and 2 compare the much more subtle difference between two makes of motor-pump. Both were pumping at the same flow rate, and generated pulses of about the same frequency. These are the fundamental peaks in each spectrum below $100 \mathrm{~Hz}$. These curves indicate a problem with evaluating the noise level of the sampler in this way: although curve 1 has larger noise components than curve 2 , and a greater overall RMS level as well, curve 1 represents the least annoying or quieter pump, as judged by several people. This may be because the fundamental component of the Bendix pump is at a lower frequency and the peaks between 100 and $300 \mathrm{~Hz}$ are absent, thus making the pump harder to hear. 


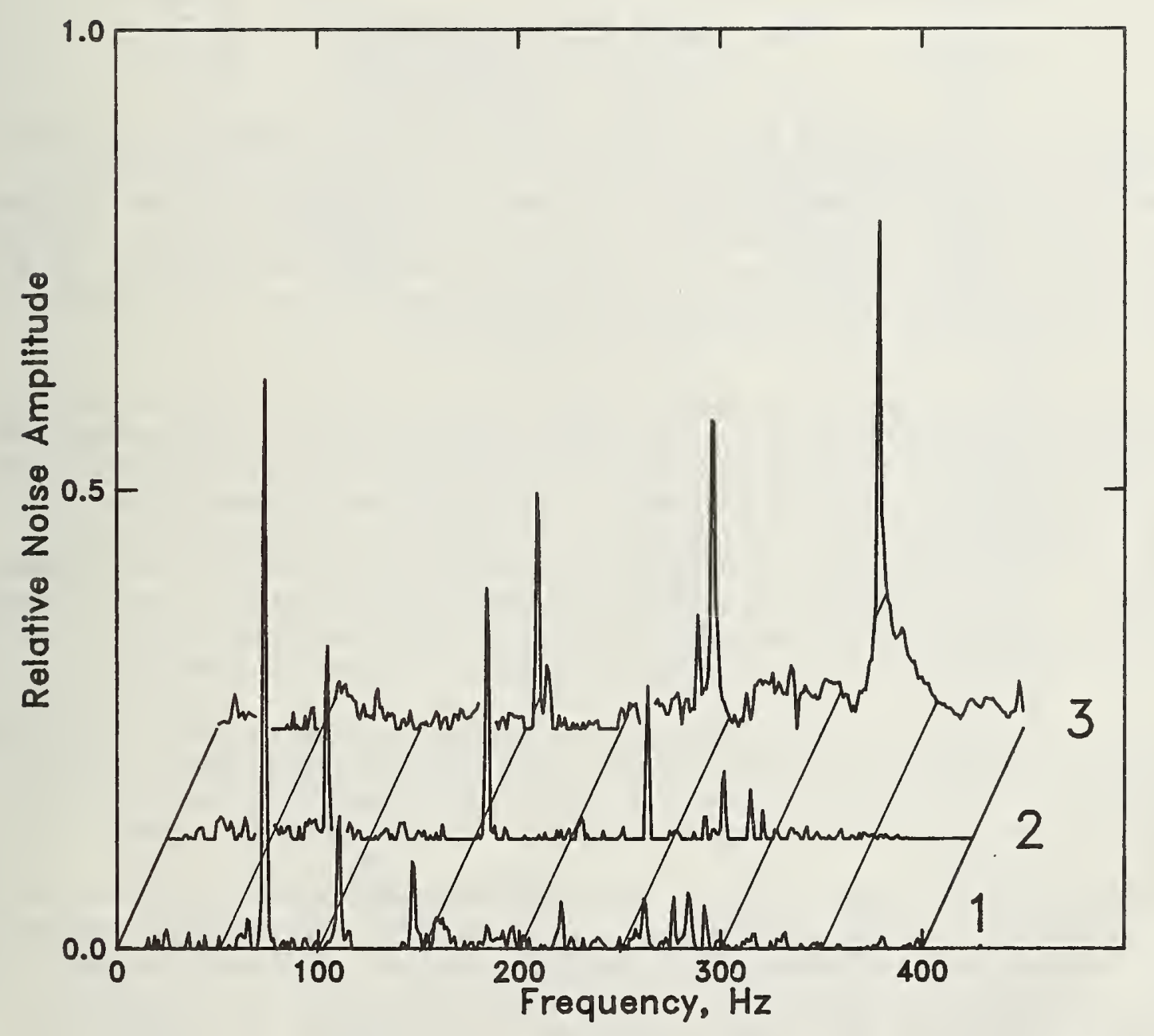

Figure 8. Sampler noise measurement. These frequency spectra are representative of measurements taken to select the most quiet sampler configuration. Relative noise amplitude, in $\mathrm{Pa} / \mathrm{Hz}$, is plotted against frequency in $\mathrm{Hz}$. The curves represent: 1. The normal NBS sampler configuration, Bendix pump, case shut (total relative RMS noise, 0.67); 2. Gilian pump, case shut (total RMS $=0.55) ; 3$. Gilian pump with case open (total RMS $=1.13$ ). See text for discussion. 


\title{
SECTION 7
}

\author{
WIND TUNNEL TEST OF INLET
}

Sampling efficiency is defined as the ratio of the number of particles per volume of air drawn through the inlet to the number of particles per volume of ambient air. Determination of the latter requires the use of ideal or isokinetic probes, which in turn requires that one know the air velocity. This is most easily accomplished by using a wind tunnel test facility $(9,21$, $27,28)$. Therefore we have designed and built a low velocity wind tunnel for particulate and gas sampler testing (Figure 9).

The tunnel has an $0.46 \mathrm{~m}$ square cross section, and can provide wind speeds over the range from 0.3 to $2.4 \mathrm{~m} / \mathrm{s}$. The variation of wind speed over the cross section of the tunnel is within $7 \%$ of the average wind speed except in the $5 \mathrm{~cm}$ boundary layer at the walls. The turbulence ranges from $2 \%$ at $0.3 \mathrm{~m} / \mathrm{s}$ to $4 \%$ at $2.4 \mathrm{~m} / \mathrm{s}$. Turbulence is the RMS value of the fluctuating component of the wind velocity (parallel to the flow) divided by the steady component. Air velocities and turbulences were measured with a fast response thin film anemometer which was calibrated with a vane anemometer, which in turn was calibrated in a special low velocity wind tunnel at NBS (29).

Aerosol is injected into the tunnel, just downstream from the turbulencegenerating "mixing" grid, through a tube with an airfoil attached to its trailing side. The airfoil helps maintain a stable aerosol plume position. We kept the aerosol plume narrow so as not to dilute the test aerosol.

The monodisperse test aerosol consisted of either ammonium fluorescein dye or oleic acid tagged with the dye. All particies were sized by sedimentation. The particles were sampled through the inlet or through isokinetic probes and collected on filters. The mass of aerosol collected was deter- . mined indirectly from spectrophotometric determination of $490 \mathrm{~nm}$ absorbance of the fluorescein dye in $3 \mathrm{~mL}$ of $0.1 \mathrm{~N}$ ammonia solution. The filters used were $37 \mathrm{~mm}, 0.3 \mu \mathrm{m}$ pore size Nuclepore high flow filters. The aerosol was easily recovered from the filter by washing with the ammonia solution and the filters gave low blank readings.

Sampling efficiency was measured by determining the ratio of the particle concentration sampled with the inlet to the concentration sampled with isokinetic probes. The results are shown in Figure 10. The inlet is about $100 \%$ efficient for small particles, regardless of wind speed and inlet orientation. The collection efficiency decreases as particle size increases and wind speed increases so that, for example, less than $20 \%$ of $15 \mu \mathrm{m}$ particles are collected at $2.4 \mathrm{~m} / \mathrm{s}$, regardless of inlet orientation. For $10 \mu \mathrm{m}$ particles, there is a pronounced orientation effect above $1 \mathrm{~m} / \mathrm{s}$. For 


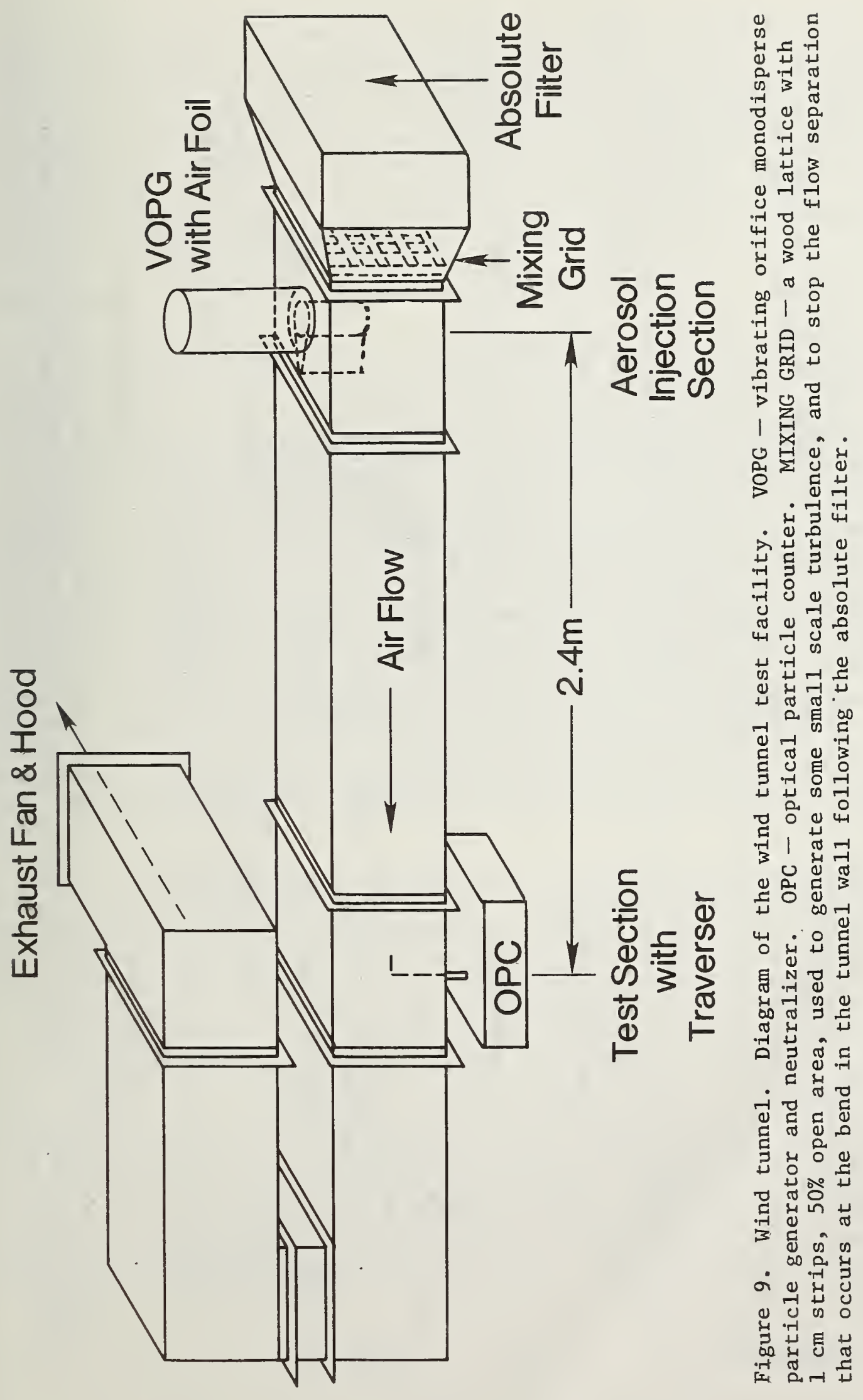



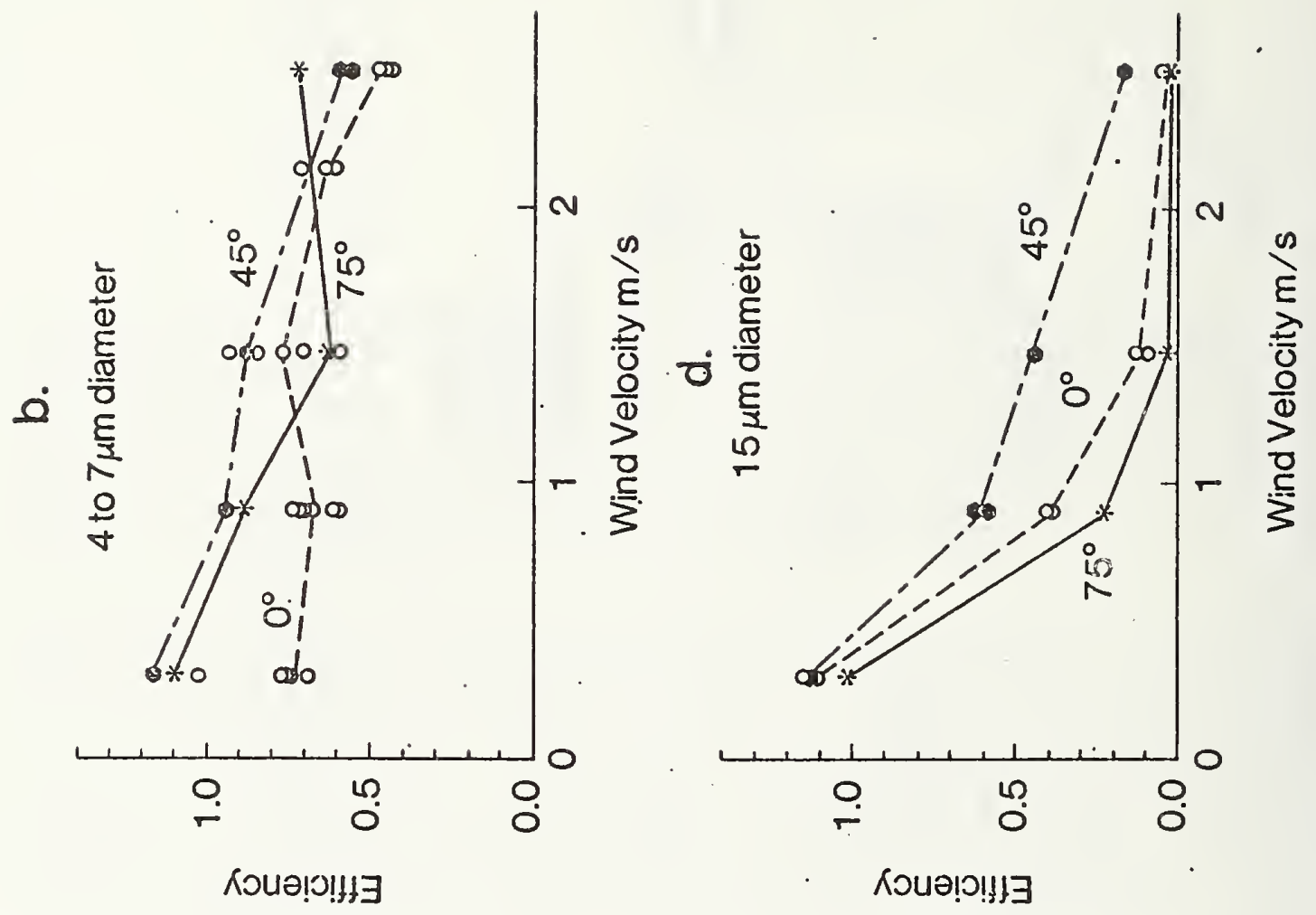

造 ซี้ำ

की

-1

-

요

$\triangle$

च व

3 의

Dั

के

욤

댕

สอ

告 :

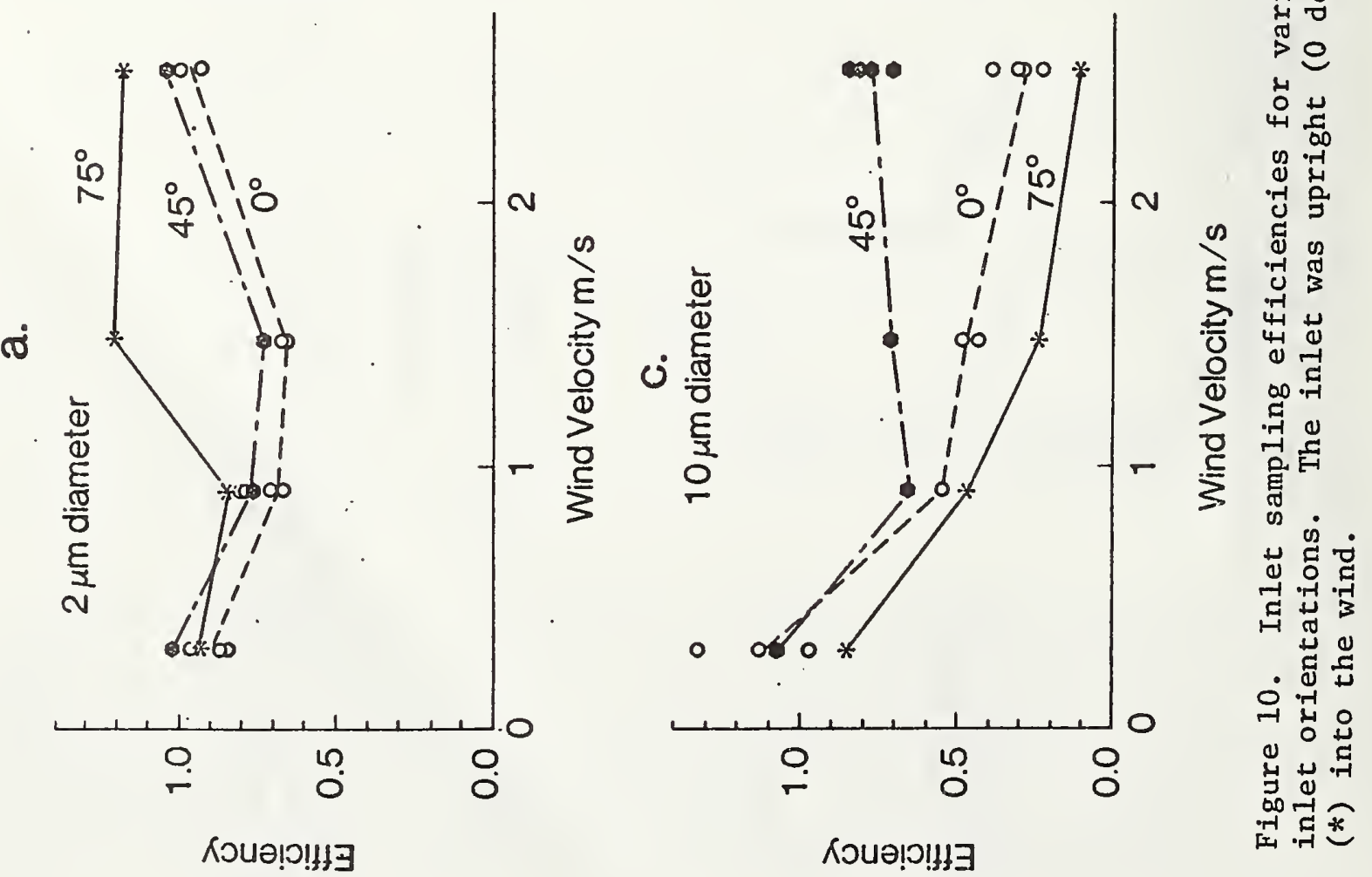


intermediate particle sizes the inlet is 75 to $100 \%$ efficient, with a slight orientation effect, and a slight efficiency decrease with increasing wind speed. The inlet over-samples large particles at low wind speeds as predicted by Davies (14) and Fuchs (28). Data taken with the NBS sampler when wind speeds are in the range of $2.4 \mathrm{~m} / \mathrm{s}$ will have to be adjusted for these effects. Average outdoor wind velocities are about $2.4 \mathrm{~m} / \mathrm{s}$. Indoor air velocities rarely exceed $0.5 \mathrm{~m} / \mathrm{s}(100 \mathrm{ft} / \mathrm{min}$ ) and are usually below $0.15 \mathrm{~m} / \mathrm{s}$ (30 ft/min) out of drafts. From Figure 10, then, we expect the sampler to sample all particles efficiently indoors.

\section{WIND TUNNEL PARTICLE PROFILES}

The particle concentration in the wind tunnel is not uniform. We have chosen to introduce the particles in a plume in order to not dilute the concentration. We have characterized the shape and stability of the plume. Figure 11 shows the relative density of a typical particle plume as a function of position across the test section of the wind tunnel. This particular curve shows the particle plume to be skewed to the right, and the test probes and inlet would be moved over accordingly. The asymmetry of the plume position is probably due to slight asymmetries in the airfoil of the aerosol injection tube: the vortex that is formed sheds more off of one side of the tube. These effects are hard to prevent though we attempted to minimize them, and have taken account of the asymmetries of plume position in our experiments. The data in figure 11 was taken by continuously traversing the test section with the probe of the optical particle counter. The multichannel analyzer, operating in the multiscaling mode, records all counts from the optical particle counter occurring during a short time period ( $0.6 \mathrm{~s})$ and stores each count total (during the $0.6 \mathrm{~s}$ ) in a single channel (there are 512 channels). This counting technique is employed during the probe traverse and generates a particle concentration profile in about 5 min $(0.6 \mathrm{~s} / \mathrm{channel}$ x 512 channels $\cong 307 \mathrm{~s}$ or $5 \mathrm{~min}$ ).

The characterization of the particle concentration profile helped detect and explain an effect that gave incorrect sampler efficiencies for the NBS and Harvard sampler when the samplers were tested intact in the tunnel. Both samplers were large enough that they had to sit on the tunnel floor in order to place the inlet near the tunnel centerline. There is a boundary layer in the tunnel, close to the walls, where the velocity is low and the particle concentration is low. The sampler cases, resting on the tunnel floor, deflected some of this boundary layer up and over the sampler, creating a "dead space" very sparse in particles around the inlets of the samplers. When the inlet or cyclone was isolated from the body of its sampler, this effect disappeared even when the inlets were placed exactly where they would have been had they been mounted on the respective sampler case. This effect made the collection efficiencies of the samplers appear artificially low, except for the NBS sampler with the inlet fully extended. In this latter case, the inlet extends far enough that it projects into an unperturbed region of the aerosol plume. 
Our wind tunnel is too small to test intact samplers because we are not able to fill the tunnel homogeneously with aerosol and even the smallest samplers block more than $5 \%$ of the tunnel cross section. When more than $5 \%$ blockage occurs, usually aerodynamic testing becomes invalid.

\section{Horizontal Particle Concentration Profile}

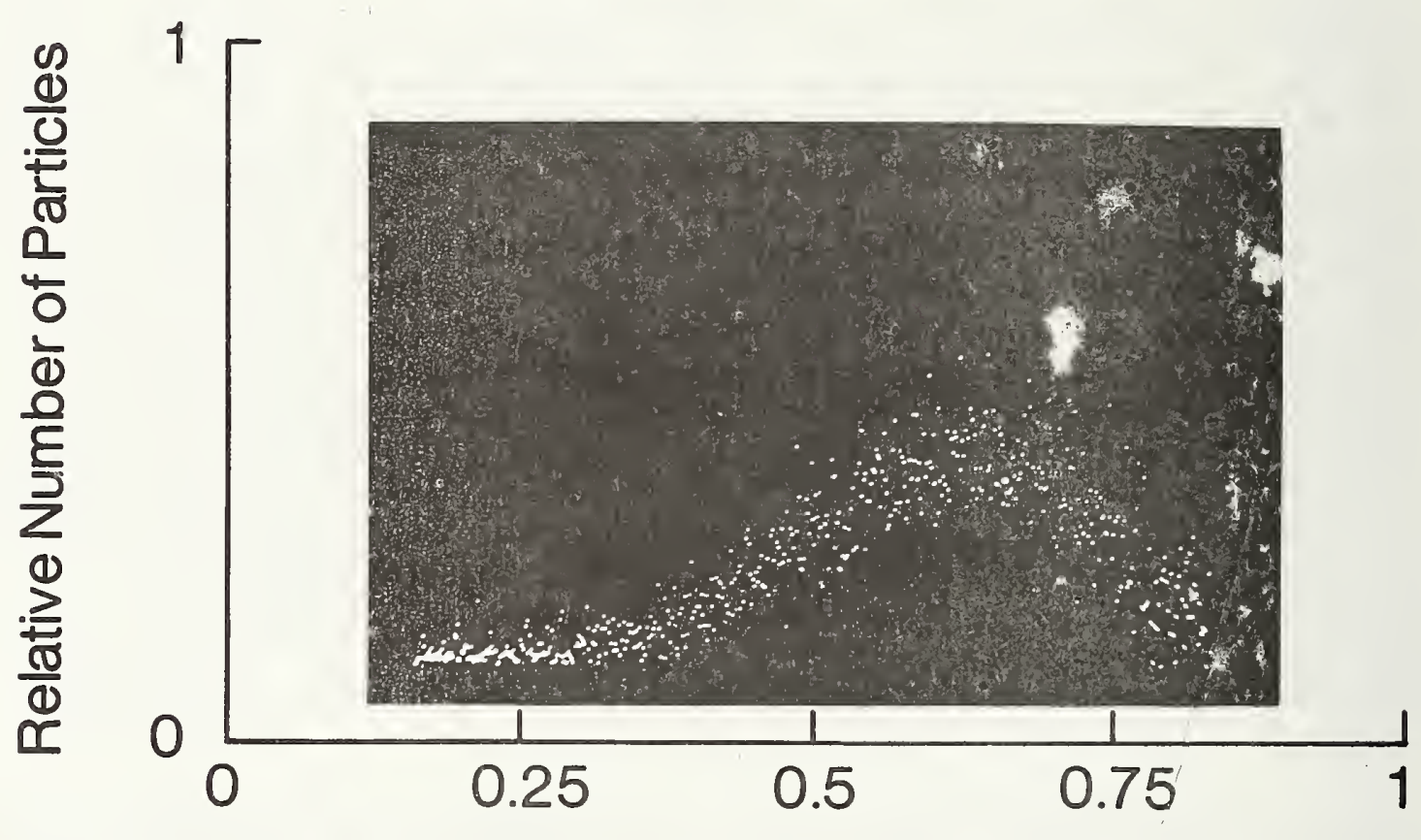

\section{Normalized Horizontal Distance}

Figure 11. Horizontal particle concentration profile. This curve is an example of a particle profile in the test section of the wind tunnel. The relative number of particles counted is plotted vs. probe position across the tunnel. This curve shows the aerosol plume to be skewed to the right. 


\section{SECTION 8}

\section{CUT TEST OF CYCLONES}

On request, we measured the collection efficiencies of two cyclone samplers as a function of particle diameter. The collection efficiency of a cyclone is the number of particles collected by the cyclone divided by the sum of the number of particles that penetrate the cyclone plus the number that are collected by the cyclone. The first cyclone is the $10 \mathrm{~mm}$ nylon unit used widely in the U.S. for industrial hygiene applications. This cyclone was tested under typical conditions, i.e., highly pulsating flow averaging $1.7 \mathrm{~L} / \mathrm{min}$ as with the Harvard sampler (John Spengler, Harvard Medical School). The second cyclone is an aluminum unit made by $\mathrm{H} \& \mathrm{H}$ of Toronto, Canada, and loaned to us by Bob Stevens (ESRL of EPA, Research Triangle Park, N.C.). The $\mathrm{H} \& \mathrm{H}$ cyclone flow rate was $1.7 \mathrm{~L} / \mathrm{min}$ smooth flow. The tests were run under pseudo-static conditions using oleic acid aerosol tagged with fluorescein dye as the test aerosol. Collection efficiencies were calculated as the ratio of the amount of dye inside the cyclone to this amount of dye plus the amount in the backup filter. The cyclones and backup filters were washed with ethanol. The ethanol wash $(3 \mathrm{~mL})$ was recycled three times through cyclone during the wash process. The amount of fluorescein particulate found on the filter and in the body of the cyclone sampler was measured at $490 \mathrm{~nm}$ using a laboratory spectrophotometer. The measured collection efficiencies are shown in Figure 12, along with the respirable curve for comparison. (Note that the $\mathrm{H} \& \mathrm{H}$ cyclone was not intended to have the AEC respirable cut characteristics, but to sample larger particles.) The 50\% cut point for the nylon cyclone as used with the Harvard sampler is $2.5 \mu \mathrm{m}$. In general, the cut curve is shifted to slightly smaller sizes in comparison to the respirable distribution curve, but the steepness of the cut and the respirable distribution curve are about the same. The $\mathrm{H} \& \mathrm{H}$ cyclone has a $50 \%$ cut point at about $5.5 \mu \mathrm{m}$, with a slightly broader cut curve.

\section{WIND TUNNEL TESTING OF CYCLONES}

The nylon cyclone and the $\mathrm{H} \& \mathrm{H}$ cyclone were tested in the wind tunnel to measure the effects of wind speed on sampling efficiency. The tests were run with nominal one micrometer aerodynamic diameter particles made with an atomizer and fluorescein solution (as described on page 29 in this report - a mass size distribution is given there). The results are shown in Figure 13 , where the angle of orientation is the angle between the wind tunnel axis and a line from the center of the cyclone through the center of the air inlet. Zero degrees is with the inlet facing head-on into the wind. The inlets of both cyclones are canted with respect to this latter direction by 90 and 180 degrees). There is a lot of scatter in the data, due to the difficult nature 
of the experiments and that the data points represent single measurements not averages. The effects of wind speed are slight with the nylon cyclone showing a larger decrease in efficiency at the higher wind speed than the $\mathrm{H} \& \mathrm{H}$ cyclone. Effects of orientation also were measured for the $\mathrm{H} \& \mathrm{H}$ cyclone. The effects are minimal, with a slight reduction in efficiency when the opening is downwind $\left(180^{\circ}\right)$.

Note that these wind tunnel tests were done on isolated cyclones, not on cyclones mounted on a sampler or attached to a person as they would normally be used in practice. 


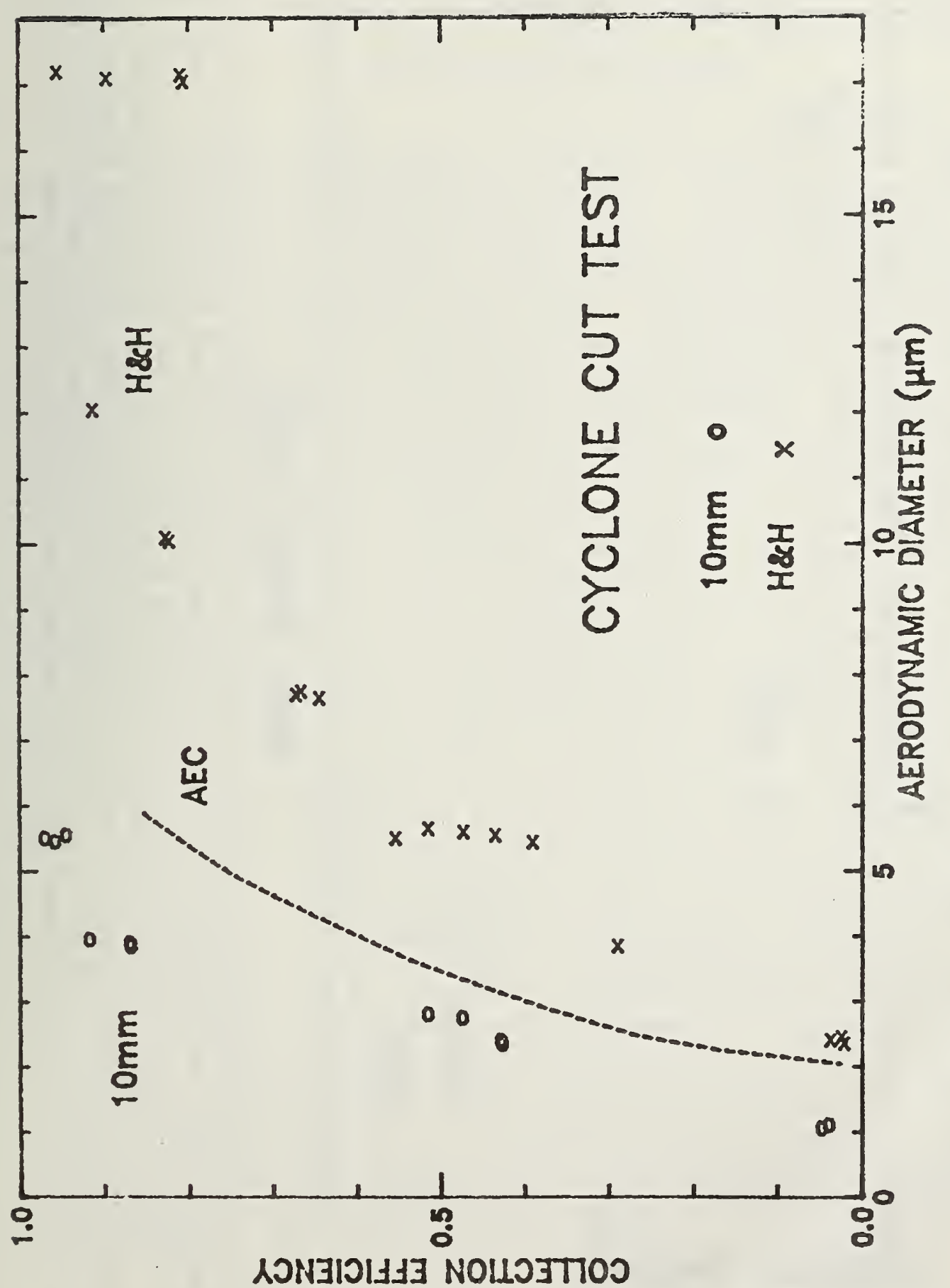

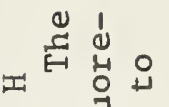

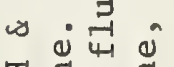

平范

ฮै

रु่

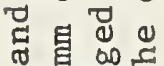

年

구워

जी

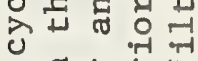

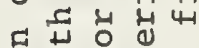

团㟧崖

政

चु

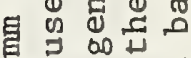

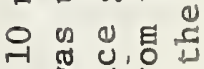

3 .

考出出

न्ते

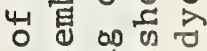

का

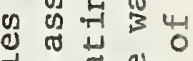

ग 0

員点字苛

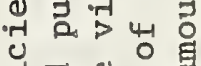

.

出岇出。

(1) है क्ष

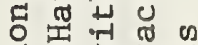

- 3 年

过包出 年草选

0 i 0

वृ न्त

巳 仓

E

०-

$\therefore$ व क क

d) 100

?

7 .

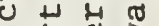

म

ป ถูก

- क तु

$\Rightarrow$ 菏

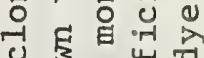

० 34

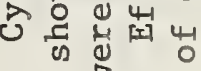

نे क्न

न 1 मे ते (4) नु $\rightarrow 00$ 嵌

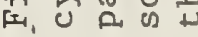




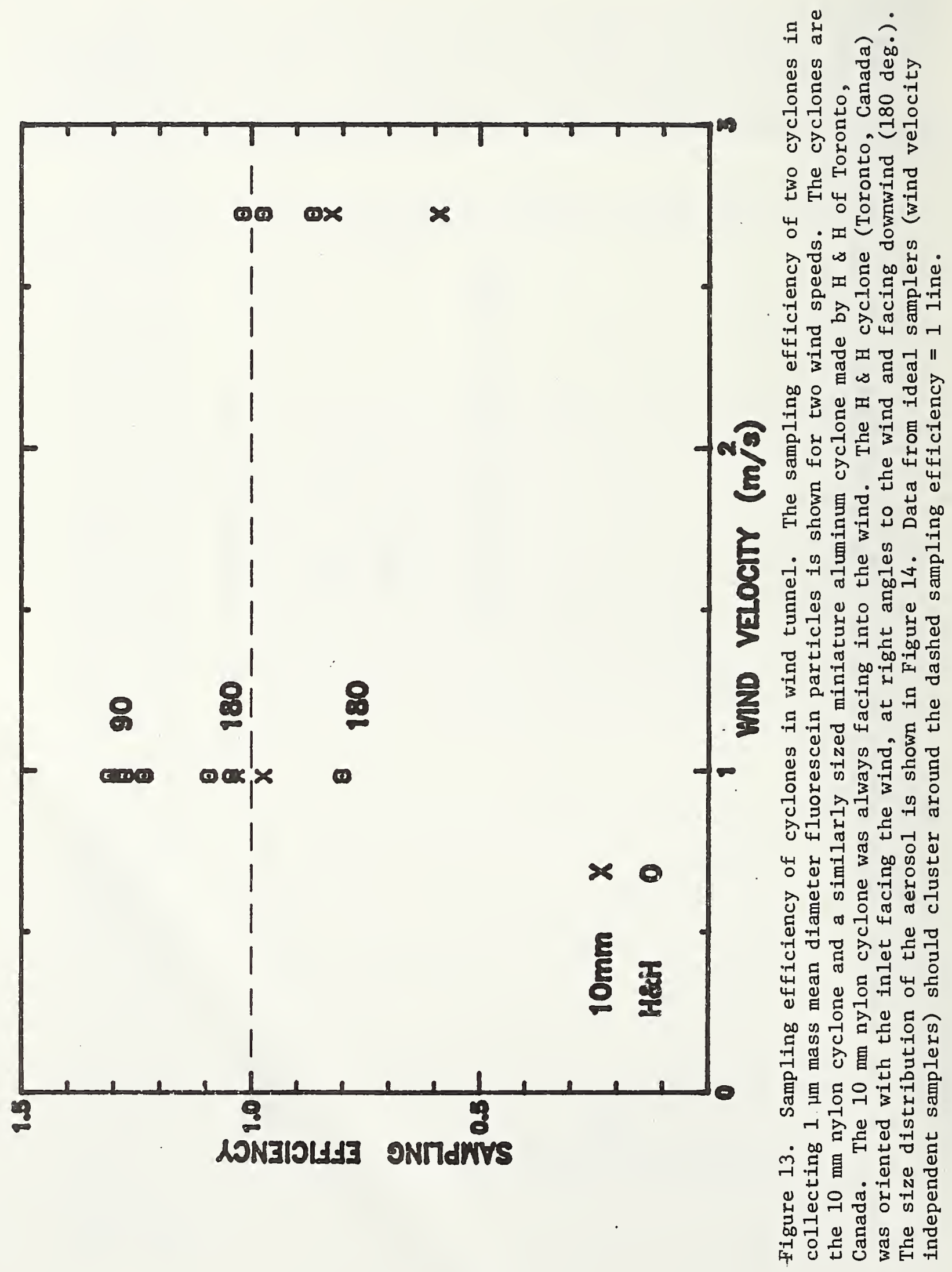




\section{SECTION 9}

\section{ATOMIZER SIZE CALIBRATION}

To make a concentrated plume of respirable aerosol in the wind tunnel, we atomized an ammonium fluorescein solution. The atomizer generates a high concentration of small polydisperse particles. Because wind tunnel characterization and sampler efficiency measurements depend on collecting measurable amounts of particles, we used an atomizer generator for some of the tests in order to decrease the length of the tests. For example, one collection of $2 \mu \mathrm{m}$ aerosol made with the vibrating orifice generator took over two hours to get the required mass of dye for an absorption reading. The same collection using aerosol generated by the atomizer took 5 minutes. The aerosol was generated as follows: a $4 \mathrm{mi}$ aliquot of $.69 \mathrm{~g} / \mathrm{L}$ solution of ammonium fluorescein was put into a DeVilbiss glass medicinal atomizer (glass nebulizer 非40). The atomizer was supplied with dry air at $4.5 \mathrm{~L} / \mathrm{min}$. The atomizer was not modified in any way, except that the rubber squeeze bulb was replaced with the air supply hose. After generation, the aerosol followed the same procedure for introduction into the tunnel as an aerosol generated with the vibrating orifice generator. This procedure included dilution with $1 \mathrm{~m}^{3} / \mathrm{h}$ dry air and charge neutralization. For size calibration runs or for testing, the aerosol was sampled at the other end of the wind tunnel. The atomizer was run for $5 \mathrm{~min}$, then the remaining solution was discarded and the atomizer loaded with fresh solution for another run. The size distribution shifted slightly during the 5 minutes of a collection, presumably due to increased concentration of the solution in the atomizer resulting from evaporation of the solvent. Therefore, all size measurements are averaged over the 5 minute collection time. The mass size distribution was calculated from the number size distribution, which was measured with a Climet CI-208 optical particle counter and a pulse height analyzer. Because the fluorescein particles absorb strongly, they appear to the Cimet to be roughly half the diameter of clear liquid particles that were actually the same aerodynamic diameter. The optical particle counter was therefore calibrated with monodisperse fluorescein particles made with the vibrating orifice generator. The largest particles were sized by sedimentation in air. The sizes of the smaller ones were calculated by dilution factors (24) from the larger sizes. The mass size distribution is shown in Figure 14. The mass mean diameter is $0.95 \mu \mathrm{m}$, and most of the mass is confined to aerodynamic diameters between 0.3 and $2 \mu \mathrm{m}$. This aerosol is nominally called $1 \mu \mathrm{m}$, for the wind tunnel tests of the samplers, where the other larger sizes of aerosol were made with the vibrating orifice generator. Note that very little, if any, of the aerosol is larger than $3 \mu \mathrm{m}$ : all of this test aerosol is clearly respirable. 


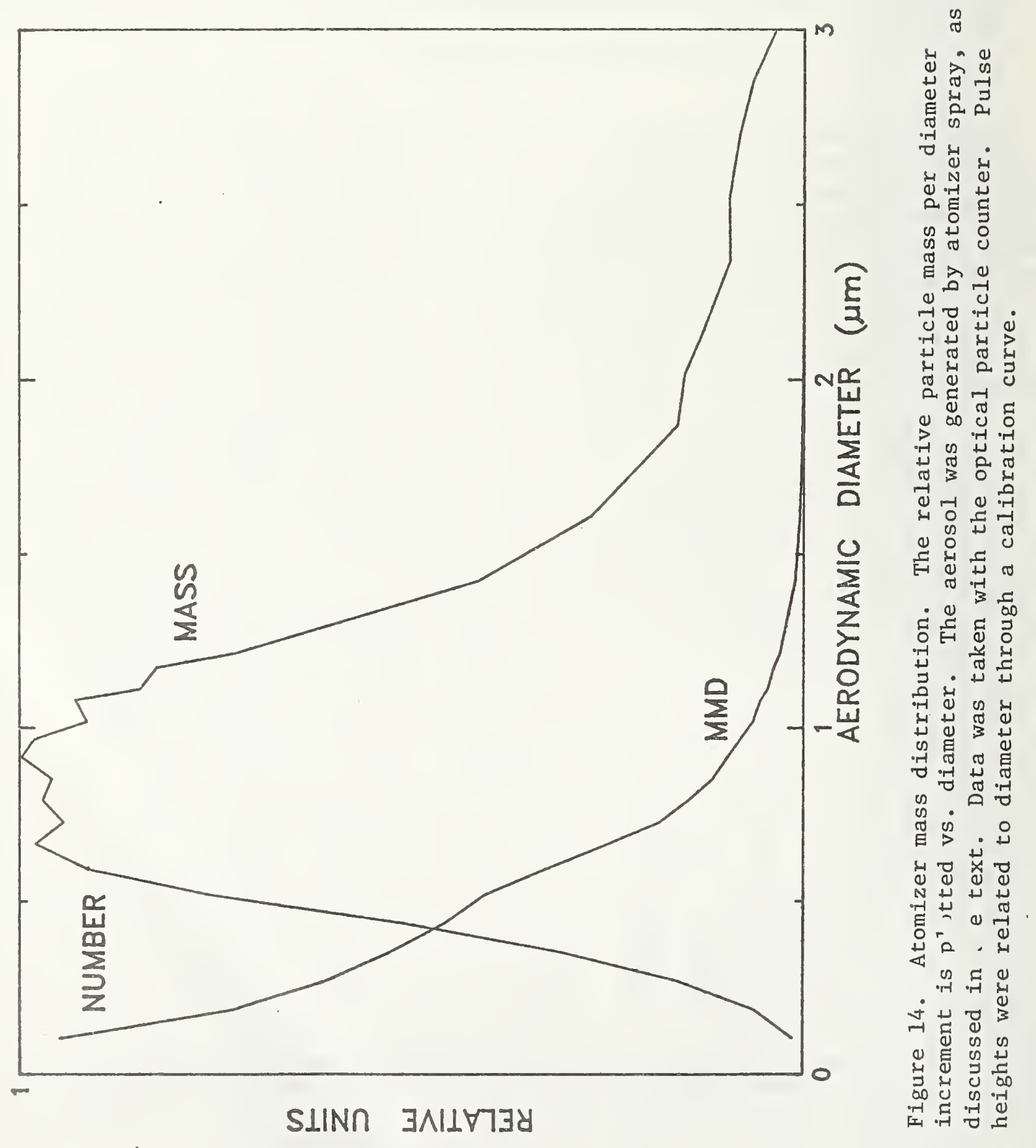




\section{REFERENCES}

1. Miller, F., D. E. Gardner, et a1.: J. Air Pollut. Control Assoc. 29:610 (1979).

2. Dockery, D. W. and J. D. Spengler: J. Air Pollut. Control Assoc. 31:153 (1981).

3. Repace, J. L. and A. H. Lowrey: Science 208:464 (1980).

4. Dzubay, T.: EPA, Research Triangle Park, Personal communication, 1980.

5. Parker, R. D., G. H. Buzzard, T. G. Dzubay, and J. P. Bell: Atmos. Envirn. 11:617 (1977).

6. Cahill, T. A., et al.: J. Air Pollut. Control Assoc. 27:675 (1977).

7. John, W., G. Reisch1, S. Goren, and D. Plotkin: Atmos. Envirn. 12:1555 (1978).

8. John, W., S. Hering, G. Reisch1, and J. J. Wesolowski: Fina1 Report, Interagency Agreement ARB A7-139-30 Air and Industrial Hygiene Laboratory Section, Lab. Services, Berkeley, CA CA/DOH/AIHL/SP-21 (February 1980).

9. Caplan, K. J., L. J. Doemeny, and S. D. Sorenson: Am. Ind. Hyg. Assoc. J. 38:83 (February 1977).

10. Turner, W. A., J. D. Spengler, D. W. Dockery, and S. D. Colome: J. Air Pollut. Control Assoc. 29:747 (1979).

11. Treaftis, H. N., T. F. Tomb, and C. D. Taylor: Am. Ind. Hyg. Assoc. J. $39: 891$ (1978).

12. G. A. Kuhlmey, B. Y. H. Liu, and V. A. Marple: A Micro-orifice Impactor for Sub-micron Aerosol Size Classification. The 89th National Meeting of the American Institute of Chemical Engineers in Portland, Oregon. Particle Technology Laboratory Pub1. No. 427, August 20, 1980.

13. Fuchs, N. A.: Atmos. Envirn. 9:697 (1975).

14. Davies, D. N.: Brit. J. App1. Phys. (J. Phys. D.) 1:921 (1968).

15. Bien, C. T. and M. Corn: Am. Ind. Hyg. Assoc. J. 32:453 (1971). 
16. Agarwal, J. K. and B. Y. H. Liu: Am. Ind. Hyg. Assoc. J. 41:191 (March 1980).

17. May, K. R., N. P. Pomeroy, and S. Hibbs: J. Aerosol Sci. 7:53 (1976).

18. Ogden, T. I. and J. L. Birkett: Ann. Occup. Hyg. 21:41 (1978).

19. Pattenden, N. J. and R. D. Wiffen: Atmos. Envirn. 11:677 (1977).

20. Raynor, G. S.: Am. Ind. Hyg. Assoc. J. 31:294 (December 1970).

21. Liu, B. Y. H. and D. Y. H. Pui: p. 383 in EPA Proceedings: Advances in Particle Sampling and Measurement, Daytona Beach, F1 (1979) EPA-600-980-004 (January 1980).

22. John W. S. M. Wa11, and J. J. Wesolowski: Final Report. EPA Grant Number R806414-02. CA/DoH/AIHL/SP27 Nov. 1981.

23. Liu, B. Y. H., D. Y. H. Pui, K. L. Rubow, and G. A. Kuhlmey: EPA Progress Report, May 1978, EPA Grant R 804600, T. G. Dzubay, project officer.

24. Berglund, R. M. and B. Y. H. Liu: Envirn. Sci. Techno1. 7:147-153 (1973).

25. Whitby, K. T., R. B. Husar, and B. Y. H. Liu: J. Colloid Interface Sci., 29:177 (1972).

26. Smith, W. B., K. U. Cushing, M. C. Thomas, R. P. Wilson, and D. B. Harris: Some Aerodynamic Methods for Sampling Inhalable Particles. p. 316 in Proceedings: Advances in Particle Sampling and Measurement (Daytona Beach, FL, October 1979) EPA-600/9-80-004 Environmental Protection Agency (January 1980).

27. Wedding, J. B., A. R. McFarland, and J. E. Cermak: Envirn, Sci. Technol. $11: 387$ (1977).

28. Fuchs, N. A.: The Mechanics of Aerosols. Pergamon Press, New York, 1964, p. 111 .

29. Purte11, L. P. and P. S. Klebanoff: A Low-Velocity Air Flow Calibration and Research Facility. NBS Tech Note 989 (March 1979). 
SAMPLER PARTS LIST

FILTER HOLDERS

Company: Millipore Corp., Order Service Department, Bedford, MA 01730 Telephone: (617) 275-9200

Item: Aerosol Monitor Case, $37 \mathrm{~mm}$ diameter, 50/pk

Cat 非000037A0 \$46.30 (8/21/80)

Extra rings are needed:

Item: Styrene monitor rings $100 / \mathrm{pk}$

Cat 非M000-037-RS $\$ 27.20 \quad(8 / 80)$

FILTER HOLDER PRESS

A $1.630 "$ rod sliding in $1.690^{\prime \prime}$ id tubing works well.

Portable drill press mount might work well for loading many samples.

COARSE FILTERS

Company: Nuclepore Corp., 7035 Commerce Circle, Pleasantön, CA 94566 Telephone: (415) 462-2230

Item: $8 \mu \mathrm{m}$ (nominal) pore Apiezon coated $37 \mathrm{~mm}$ polycarbonate filters Cat 非110832, Lot 非1ABC-3-4 \$94.00/100 filgers $(8 / 80)$

FINE FILTERS (PTFE fiber)

Company: Ghia Corp. 7071 Commerce Circle, Pleasanton, CA 94566 Telephone: (415) 846-8270

Item: $3 \mu \mathrm{m}$ pore size Zeflour filters, $37 \mathrm{~mm}$ diameter (heavy backing) $\$ 98.00 / 100$ filters $(8 / 80)$

IONIZING UNITS (polonium 210 - half-life $=138.4$ days - reorder regularly)

NOTE: The Nuclepore filters are very difficult to handle and to weigh without neutralizing the static electrical charges that easily build up on them.

Company: Nuclear Products Corp., 2519 N. Merced Ave., South Elmont, CA 91733

Telephone: (213) 283-2603 
Company: Zero East Division, 288 Main St., Monson, MA 01057

Telephone: (413) 267-5561

Roger St. Martin - Local Representative*

Pyttronics, 8220 Wellmoor Ct., Savage, MD 20863

Telephone: (301) 972-0780 Attn: Vernell Jackson

North Carolina Representative

Kirkman Electronics, Inc., 901 W. Second St. (Drawer K - Alem Station), Winston Salem, NC 27108

Telephone: (919) 722-9131

Item: Aluminum Carrying Case

Cat 非C $7010 \quad \$ 42.10 \quad(7 / 80)$

NOTE: Inlet hole punched with $1 "$ conduit (chassis) punch - approx. $16 / 16^{\prime \prime}$ hole.

RUBBER FEET

Blobbs of RTV silicone rubber cement make functional, though not elegant, feet.

Company: Green Rubber Co., 160 Second St., Cambridge, MA 02142

Telephone: (617) 547-7655

Item: white bumbers SJ5018 $\$ 30 / 100 \quad(3 / 81)$

FOAM

(For case lining to damper noise, vibration)

Company: Green Rubber Co., 160 Second St., Cambridge, MA 02142

Telephone: (617) 547-7655

Item: 3 " $\times 12^{\prime \prime}$ 非58 polyfoam, 1/4" thick

$\$ 2.88 / \mathrm{sq}$. yd. $(3 / 81)$

Item: $5^{\prime \prime} \times 5^{\prime \prime}$ polyfoam 非 density, 3/4" thick (not used) $\$ 7.14 / \mathrm{sq}$. yd. $(3 / 81)$

\section{BATTERIES}

Company: Gould Inc., Portable Battery Division, 931 Van Dalia St., St. Pau1, MN 55114 Attn: Greg Taylor

Item: NiCad cells plastic insulation, solder lugs

C cells (15 hours) - Cat \#2.0SCL (18 hours) \$6.05 (10/80)

D cells (35 hours) - Cat \#4.0SCL (38 hours) $\$ 9.90$

F cells - Cat 非 7.0 SCL (64 hours) $\$ 15.85$ 
MSCL. ITEMS

Item: Velcro tape, used to attach battery pack and motor to case.

Item: GE RTV Silicone rubber cement, used to make all rivets air tight.

Item: (Kodak) Plastic $35 \mathrm{~mm}$ film can 9 muffler for pump exhaust).

NOTE: The output of the motor goes via 1/4" id. flexible rubber hose to one film can, then via 1/4" id. tygon to the other film can and then to the outlet fitting, which is a plastic hose-hose connector cut in half. The tygon is used only if. it is stiff and can be force-fit into undersize holes in the plastic film can.

Item: Rubber hose and fitting for case exhaust)

(Exhaust line must not leak into case)

Item: Battery connector, any small 2 lead connector to make battery pack removable. Note: the batteries have pins that are recessed so that when the battery is unpluged (sampler off), there is no chance of metal parts inside the case causing a short.

NOTE: The battery connector serves as the on/off switch. The batteries are intended to be changed and charged separately, probably where the filter packs are changed.

Item: Duct tape to wrap batteries together and insulate them.

Item: 2" $\times 6^{\prime \prime}$ board - holds battery pack with velcro.

Item: hookup wire

Item: $1 / 4^{\prime \prime}$ (copper) elbow to make sharp bends in exhaust line ( $3 / 8^{\prime \prime}$ 0.D. for $1 / 4^{\prime \prime}$ tubing), swagelok grommet 5/16" I.D. for 7/16" panel hole

INLET

See accompanying drawing and notes

NOTE: A collar of aluminum is used to securely attach the inlet to the case. A shoulder may be machined directly on the head instead.

Item: $1.5^{\prime \prime}$ aluminum bar stock

Item: Fritted stainless steel, (1/16" thick filters)

Company: Pacific Sintered Metals, 16120 S. Figueroa St. Gardena, CA 90248 Telephone: (213) 321-4595

2" disc., 1/16" thick, 2-5 $\mu \mathrm{m}$, pore size

Cat. 非FCR-2030 \$5.62 (6/80)

NOTE: \$25 minimum order 
NOTE: There are three Bendix pumps - the BDX35, BDX55, and BDX60 self contained pump units - all having the same pumping characteristics. Any of the three will perform equally well in the sampler, however, the BDX55 pump and item "b" are the only ones that will fit sideways in the case without removing the rear shaft extension. The shaft extension on the BDX60 is for a motor speed controller, and is not used in the sampler. The extension on item "a" is for a worm gear to drive a mechanical counter to count total pump cycles. This might be a useful indication of total volume.

Company: Industrial Products Corp., 21 Cavot Blvd., Langhorn, PA 19047 Telephone: (800) 523-3944 Attention: Jeanette Laster Normal delivery, 1 month, Jeanette's file is under the name D. Bright.

Item a: BDX30 pump, Part 非41 7110-0005 \$130 $\quad(2 / 81)$

Item b: BDX30 pump, Part 非41 7110-0003 \$120 (2/81)

Item $a$ has a revolution counter, item $b$ does not.

Possible alternative source of item a: John Spengler, Harvard School of Public Health; 665 Huntington Ave., Boston, MA 02115

Telephone: (617) 732-1946

Associate: William Turner 732-1245

Spengler used 50 complete BDX55 units as backups for some studies and is now through with them. He has expressed interest in selling the units: they might be less expensive than new replacement motor-pump assemblies from Bendix.

PUMP (Alternate Source)

Company: Gilian Instrument Corp., 1275 Route 23, Wayne, NJ 07470 Telephone: (201) 696-9244

Item: OEM pump, 4-6 1/m, large cam.

$\mathrm{P} / \mathrm{N} 10027$

$\$ 250 \quad(2 / 81)$

NOTE: This pump is slightly less efficient, noticeably more noisy, but durable.

Company: Brailsford \& Company, Inc., Milton Road, Rye, NY 10580 Telephone: (914) 967-1820

Item: TD-4x2L, 6 volt pump $\$ 140.00$

NOTE: - Only half as energy efficient as the Bendix, but very durable. 


\section{NBS PARTICLE SAMPLER OPERATION AND MAINTENANCE}

- Schematic of sampler (page 2)

- Filters

1. Handling

2. Storage

3. Weighing

4. Mounting in holders

5. Loading into sampler

6. Flow rate measurement

- Batteries and charging

- Inlet

1. Impactor ring replacement

2. Extension to full length 
A $6.8 \mu \mathrm{m}$ grease coated Nuclepore filter is used for coarse particle collection and a $3 \mu \mathrm{m}$ pore size Ghia Zeflour teflon fiber filter for fine particle collection. The filters are neutralized with a $500 \mu \mathrm{c}$ polonium source to remove static charges. The Nuclepore fiber is especially hard to handle directly from the package, but after neutralization it becomes flat and flexible. It can be mounted with either side up since both sides are identical. The Zeflour filter should be mounted with the soft, smooth (velvet-like) PTFE side up. This can be easily determined by touching one of the filters although that filter can not then be used for collection. However, with practice, one can recognize the back side by observing the grain like structure of the support material.

After the filters are neutralized and ready for weighing, an identification number is placed near the filter edge which contributes less than $1 \mu$ to the weight.

The filters are weighed on a Me22 (Mettler) microbalance. The Nuclepore typically weighs $\sim 10 \mathrm{mg}$ and the Ghia Zeflour welghs from 100 to $150 \mathrm{mg}$. For weighing, the filters are fully neutralized and the relative humidity of the weighing room is held as constant as possible $50 \pm 11 \%$. An aluminum foil is used as a tare weight with each filter to detect balance fluctuation and systematic weighing errors.

After weighing, the filters are mounted in a $37 \mathrm{~mm}$ Millipore holder. This requires 3 rings and a top and bottom cap. The filters should be placed in the three ring assembly and then the assembly should be pressed tight with considerable force to make sure the filters do not slip out. Nothing else supports the filters, so this ring tightening procedure is essential. Once the filters are mounted, they can be stored with the top and bottom closed.

The series filter assembly is mounted on the back end of the inlet after the top and bottom caps are removed. An elastic strap helps to hold the filter unit tightly in place. No tubing is attached to the filter pack (see schematic of sampler). Once the filters are loaded, fully extend the inlet. Connect the pump to the battery pack and close the 1id. Take care that none of the exhaust tubes are pinched in the process. Make a flow rate measurement using the rubber adapter provided in the shipment. Slip the adapter over the inlet entrance so that the openings clear the sealing part of the adapter. Hook adapter to a low resistance flow meter such as a model TSI thermocouple gauge. Rotometers and units with several inches of $\mathrm{H}_{2} \mathrm{O}$ will restrict the flow and will not give an accurate measure of the flow rate. A bubble meter will work if its pressure drop is $2.5 \mathrm{~cm}$ of water or less. The flow should be $6 \mathrm{~L} / \mathrm{min} \pm 0.5 \mathrm{~L} / \mathrm{min}$. 
The sampler should be able to run at $6 \mathrm{~L} / \mathrm{min}$ for $25-35$ hours without charging the battery packs. Charging of the battery packs is done by removing the battery and connecting them overnight to the charger provided. The charger light (LED) Indicates either battery charging or when the charger power cable is disconnected, battery discharging through the LED.

After completing a sampling period, the filters are removed, capped, and stored in the humidity temperature controlled weighing room. After 24 hours equilibration the filters are reweighed. The foll tare is used as comparative "standard" to correct for balance drift.

- Inlet

The impacting surface inside the Inlet is a sintered stainless steel disc, soaked with vacuum pump oil. The disc is held in place by friction and can be removed by pushing from the bottom of the inlet, through the small hole in its mounting shoulder. Loose discs can be made to fit snuggly by drying a layer of glue on the outer edge of the disc before insertion.

When the discs become dirty, they may be wiped clean and a few drops of vacuum pump oil added. Allow it to sit overnight and blot away any excess oil. An alternate procedure, if preferred, is to remove the disc, clean it in acetone, soak it overnight in vacuum pump oil, and then drain and blot off excess oil before reinserting the disc into the inlet. 
NBS-114A (REV. 2.80)

U.S. DEPT. OF COMM.

BIBLIOGRAPHIC DATA

SHEET (See instructions)

1. PUBLICATION OR REPORT NO.

NBSIR 82-2561
2. Performing Organ. Report Noo 3. Publication Date January 1983

4. TITLE AND SUBTITLE

NBS Portable Ambient Particulate Sampler (Interagency Agreement No. AD-13-F-1-535-0)

5. AUTHOR(S)

Robert A. Fletcher and David S. Bright

6. PERFORMING ORGANIZATION (If joint or other than NBS, see instructions)

7. Contract/Grant No.

NATIONAL BUREAU OF STANDARDS

DEPARTMENT OF COMMERCE

WASHINGTON, D.C. 20234

9. SPOWSORING ORGANIZATHON NAME AND COMPLETE ADDRESS (Street, CHY, StOte, ZIF)

8. Type of Report \& Period Covered

10. SUPPLEMENTARY NOTES

Document describes a computer program; SF-185, FIPS Software Summary, is attached.

11. ABSTRACT (A 200-word or less factual summary of most significant information. If document includes a significant bibliography or literature survey, mention it here)

The NBS portable ambient particulate sampler is designed to collect the respirable and inhalable particle size fractions at a sampling rate of $6 \mathrm{~L} / \mathrm{min}$ for 24 hour sampling periods. Particulates are fractionated and collected by series filtration. The collection efficiency of the inlet is measured by comparison with isokinetic probes in the wind tunnel. The collection efficiency and sampling size characteristics of two small personal cyclone samplers are also reported.

This work was sponsored by the Environmental Protection Agency under interagency agreement no. AD-13-F-1-535-0.

12. KEY WORDS (Six to twelve entries; alphabetical order; capitalize only proper names; and separate key words by semicolons) inhalable aerosol; inlet efficiency; isokinetic probes; portable aerosol sampler; respirable aerosol

13. AVAILABILITY

X] Unlimited

$\square$ For Official Distribution. Do Not Release to NTIS

$\square$ Order From Superintendent of Documents, U.S. Government Printing Office, Washington, D.C. 20402.

X] Order From National Technical Information Service (NTIS), Springfield, VA. 2216I
14. NO. OF

PRINTED PAGES

43

15. Price

$\$ 7.50$ 
